\title{
DETAILED ANALYSIS OF FLARES, MAGNETIC FIELDS AND \\ ACTIVITY IN THE SUNSPOT GROUP OF SEPT. 13-26, 1963
}

\author{
HAROLD ZIRIN and SUSAN WERNER \\ Mount Wilson and Palomar Observatories, Carnegie Institute of Washington, \\ California Institute of Technology
}

(Received 5 August, 1966)

\begin{abstract}
We analyze large-scale H-alpha movies of the large spot group of Sept. 13-26, 1963 together with radio, ionospheric and magnetic field data as well as white light pictures. The evolutio: of the group and associated magnetic fields is followed, and the positions of solar flares relativ to the fields are noted, along with their morphology. Although the magnetic field is deformed $\mathrm{i}$. time, characteristic field structures may be traced through the deformation as the seat of recurren homologous flares.

We find that most flares are homologous, and some are triggered by disturbances elsewhere if the region. We note events produced by surges falling back to the surface, and one flare initiater by a bright bead seen to fly across the region. In almost every case of an isolated type III radir burst, a corresponding $\mathrm{H}$-alpha brightening could be found, but not all flares produced bursts Flares close to the sunspots are most likely to produce radio bursts. Flare surface waves in the regio] all travel out to the west, because of more open magnetic field structure there. In one case (Sept. 25 a wave is turned back by the closed field structure to the east.

In almost all cases the time association of radio or ionospheric events is with the beginning o the flare or with the flash phase.

Several morphological classes of flares are noted as recurrent types.
\end{abstract}

\section{Introduction}

The study of solar flares and active regions requires large scale photography witl high resolution instruments. In 1963 we placed a half angstrom filter at the Coudı focus* of the 16-inch Climax coronagraph to make such studies, and were fortunatı to obtain several fine series of cinematograms of the large spot group that crossec the disk between September 13 and 26. Although the filter used is of an older typ without sideband suppression, the high resolution of the telescope and the goor seeing in this period led to excellent results. Cinematograms were obtained or Sept. 13, 17-19, and 22-26. Other days were missed because of clouds, part of thi above days were missed for the same reason. Pictures were taken at the rate 0 4 per minute on the $13 \mathrm{th}, 22 \mathrm{nd}, 24 \mathrm{th}, 25 \mathrm{th}$, and $26 \mathrm{th}$, but on the other days $(17,18$ and 23 Sept.) pictures were obtained at only 1 per minute, which is too infrequen to follow fast activity, but which does bring out slower changes. An importan advantage of cinematographic review is that the eye averages effects of seeing anc film grain, so that much more is seen in the film than in the individual frames.

A number of remarkable events were found on these films, which we will summa rize on a day by day basis. Several important characteristics were found:

* For this reason the image rotates in our pictures, we have tried to note the coordinate position in each photo. When not otherwise noted, $\mathrm{N}$ is at the top and $\mathrm{E}$ on the right. 
(1) In periods of numerous flares, there was continual rapid activity manifested sy motions of filaments, small rapid brightenings, surges, and waves of brightening or displacement. These waves, similar to those observed by ATHAY and MORETON 1961), are very difficult to display in single frames but are easily seen in the movies. Some are slow enough that highly accelerated movies are needed to observe the effect; thers are so fast that we need frequent pictures.

(2) Many flares appeared to be triggered by disturbances elsewhere in the region, usually by a smaller flare. In one remarkable case on September 23 (Figure 20), a bright bead was seen to fly across the region and set off a surge. (A similar event sccurred in the same area on Sept. 17.) When the surge fell back to the surface, the bead returned and a small flare followed. We of course do not know what causes the first smaller flare, nor have we made statistical analyses to prove the connection, but we consider it to be real. (These phenomena are best seen on the film and we would be glad to lend $16 \mathrm{~mm}$. prints to interested investigators.) It is obvious that a returning surge must make a substantial perturbation when it hits the surface.

(3) Almost all surges and flares are homologous, i.e., they recur in regions where there have been other flares with the same general shape and evolution. The same regions produce flares throughout the 9-day period, even though the spot configuration changes.

(4) In almost every case of a strong isolated type III radio burst, a simultaneous $\mathrm{H}$-alpha brightening could be found, usually in a particular radio-active area. The adio bursts of Sept. 25 are the best examples. Since our films cover only a fraction of the disk, the few negative results may be attributed to flares elsewhere. The radio burst usually corresponds to the beginning of the $\mathrm{H}$-alpha brightening or to the flash phase when the brightness increases discontinuously.

Unfortunately we did not observe any of the large importance 3 flares in the region, although several class 2 flares were observed. Most of the flares reported here were picked up by the various geophysical flare patrols and classed as importance 1 -flares. The fact that many of them correspond to radio bursts and some to ionospheric events makes their listing in flare compilations important. We have no physical estimate of flare importance, but it is clear that some of these 1-flares were underestimated on the basis of area alone. For example, the small brightening at 1842 UT on Sept. 25 produced a strong type III burst and a small cm burst, but was only classed as importance 1-. The large spray and explosive flare at 2309 UT (class 1-) covered the entire region and was the occasion of the expulsion of a great deal of material, yet its radio and ionospheric effects were modest. But the bright surge which triggered this explosive flare gave a large type III burst. We do not have the temerity to propose a new scheme of flare importance classification at this time, but we do feel that radio and ionospheric effects are at least as important in this regard as the $\mathrm{H}$-alpha area.

In our analysis, we have made the following assumptions: (1) Events separated in time and space by intervals very small compared to the mean interval between events may be causally connected. One event may "trigger" the next, or both may be caused by the same agent. (2) Magnetic field structure may be inferred from $\mathrm{H}$-alpha 
structure. Bright regions mark vertical, enhanced fields, dark filaments mark horizontal fields.

We now define several terms which will be used to describe the various events:

umbral flash: a flash characterized by the rapid outward motion of brightness, in a narrow sector from the umbra.

notch flare: a flare connected with a notch in the umbra or a light bridge across it. in situ flare: a flare showing only brightening of a given region, with no motion of the bright region. This flare may or may not give a surge.

explosive flare: a flare characterized by explosive outward motion and expansion of the bright region.

flash or flash phase: rapid brightening and spread of brightness in a flare unaccompanied by evident motion.

hourglass flare: filling by large flares of an hourglass shaped region bounded by the two rows of spots of opposite polarity and the neutral lines.

The above is not a classification of flares, but a listing of types observed on these and other films. A number of other interesting events were seen on the films, some of which are illustrated in the accompanying photographs. Among these were:

The development of the flare of Sept. 18 (1400 UT) which gave an X-ray burst observed by de Jager (Figure 14).

Remarkable continuous motion in the prominence of Sept. 19 (Figure 17).

The triggering of a flare on Sept. 23 by a flying bead (Figure 20), previously referred to.

A series of explosive flares from the same point on Sept. 24 and 25 (Figures 21 and 23).

A series of similar small flares accompanied by radio bursts on the 25th (Figures $24,25,26)$.

A very rapid, small umbral flash on Sept. 24 (Figure 22), which produced a substantial radio burst.

\section{Evolution of the Spot Group}

Our photos cover the period Sept. 17-26 in greatest detail; during this time we may follow the general evolution of the spots by the white light photos kindly furnished us by Bumba of Ondřejov and McIntosh of Sacramento Peak, combined with our own $\mathrm{H}$-alpha photos and those made by Ramsey at Lockheed and Sheeley at Mt. Wilson. Although the region changed shape during nine days, most of the original features could be traced through their evolution; the same is true of the magnetic field. We have information on the magnetic fields from cancelled photographic magnetograms obtained by Sheeley at Mt. Wilson on Sept. 16 and 20 (Figure 2); from the magnetic map for Sept. 18 published by Teske, Dodson, Hedeman (1964) (Figure 3) and from the Mt. Wilson spot drawings by Thomas Cragg. Data on flares is taken from the Solar-Geophysical data Part B.*

* Solar-Geophysical Data, CRPL-F, part B, National Bureau of Standards, Boulder, Colorado. 
On Sept. 17 (Figure 1a) the spot group was dominated by a large spot of S polarity with a remarkable trio of elongated spots next to it. Just east is another, somewhat smaller spot, and stretching further to the east of the large spot was a comma shaped string of spots of the same polarity (except, possibly, for the easternmost). To the northwest of the large spot appeared a triple spot of opposite polarity connected to the main group by a chain of small spots. These structures may be seen in Figure 1b,
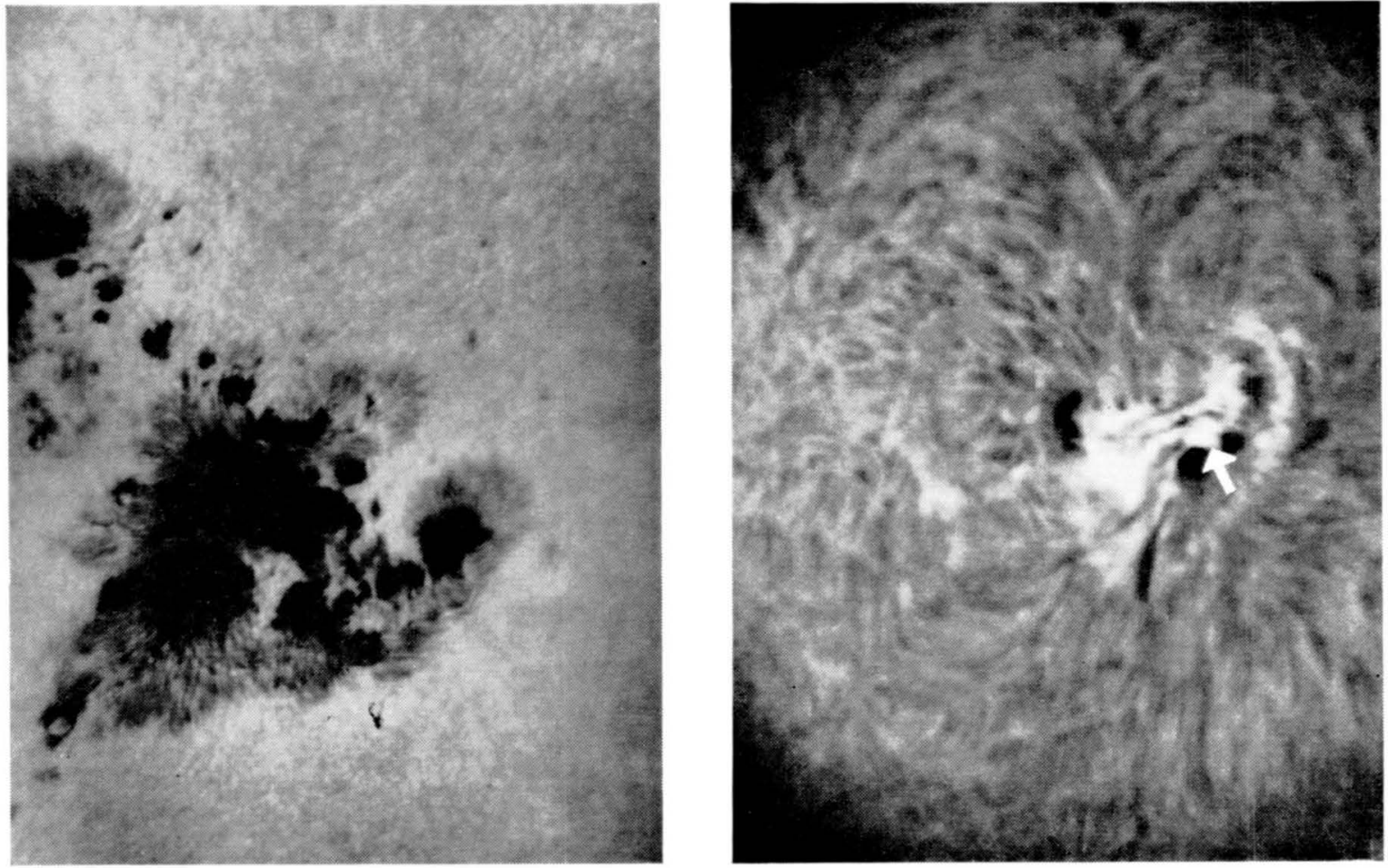

(a)

(b)

Fig. 1. (a) White light photo by V. Bumba at Ondřejov Observatory Sept. 17, 1963, 1415 UT, showing detailed structure of the group. The three elongated spots at the center are most interesting; they probably have different polarities with the neutral line winding in and around them. $\mathrm{N}$ top, E right. - (b) Simultaneous $\mathrm{H}$-alpha picture at Climax. Strands of plage follow the 3 elongated spots. On this, as in any other $\mathrm{H}$-alpha picture, such effects may occur because the dark spots reduce the apparent brightness of the overlying plages. A flare is in progress at point $\mathbf{G}$ (arrow) between 2 large spots. None of this activity can be seen on Figure 1a. (Compare with Figure 13.) N upper left, E upper right.

an H-alpha photo made at Climax at 1415 UT on the 17th. A small surge is seen to the southwest. The bright plage area filled an hourglass shaped region, between the neutral line (which runs roughly E-W) and the triple spots on one side (W), and the same line and the comma-like elongation on the E side. It appears from the magnetic data that the neutral line was not straight, but followed a winding path between and around the elongated spots; each of these had polarity opposite that of its neighbors.

The magnetic structure of the region is best revealed by the fine magnetograms made by Sheeley on the 16th and 20th (Figure 2). The Teske, Dodson and Hedeman 

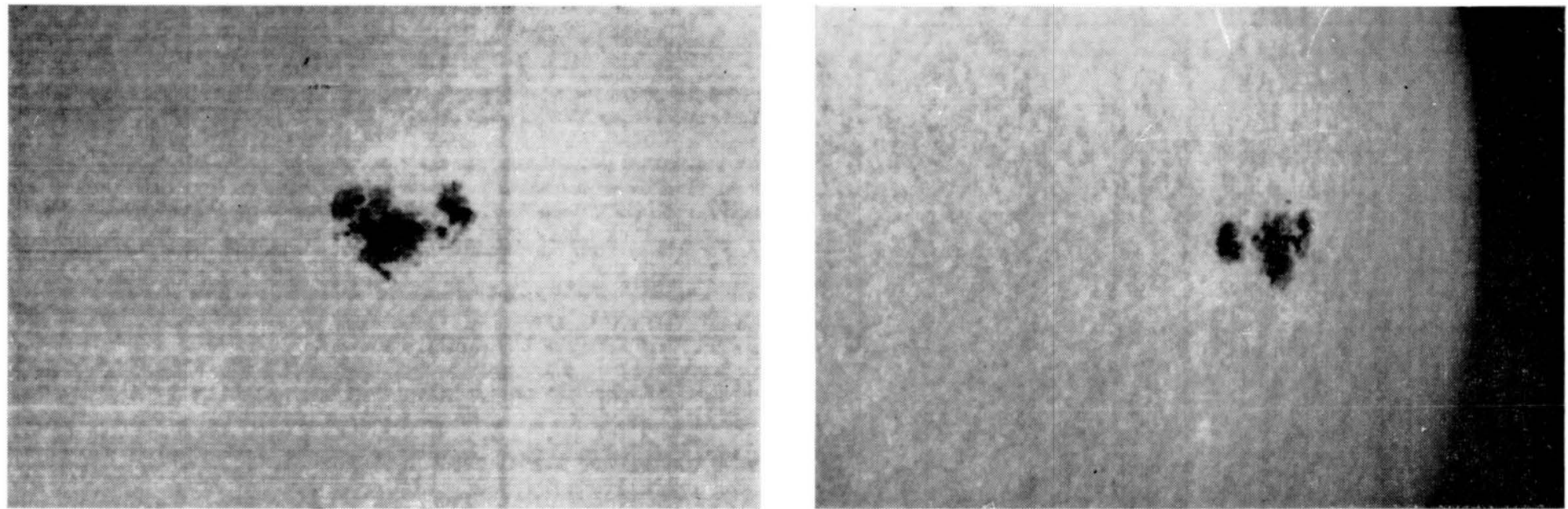

(c)

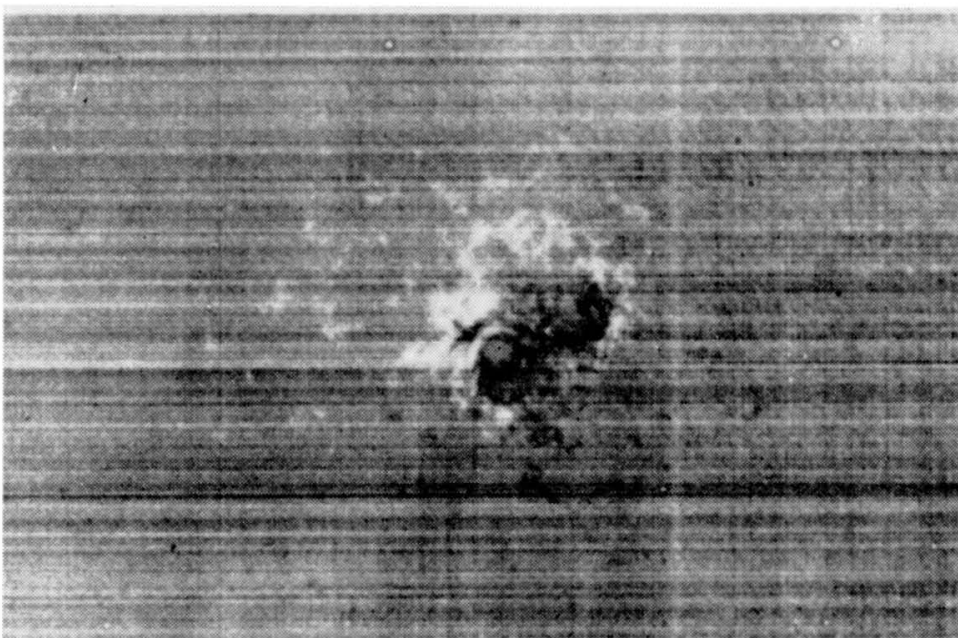

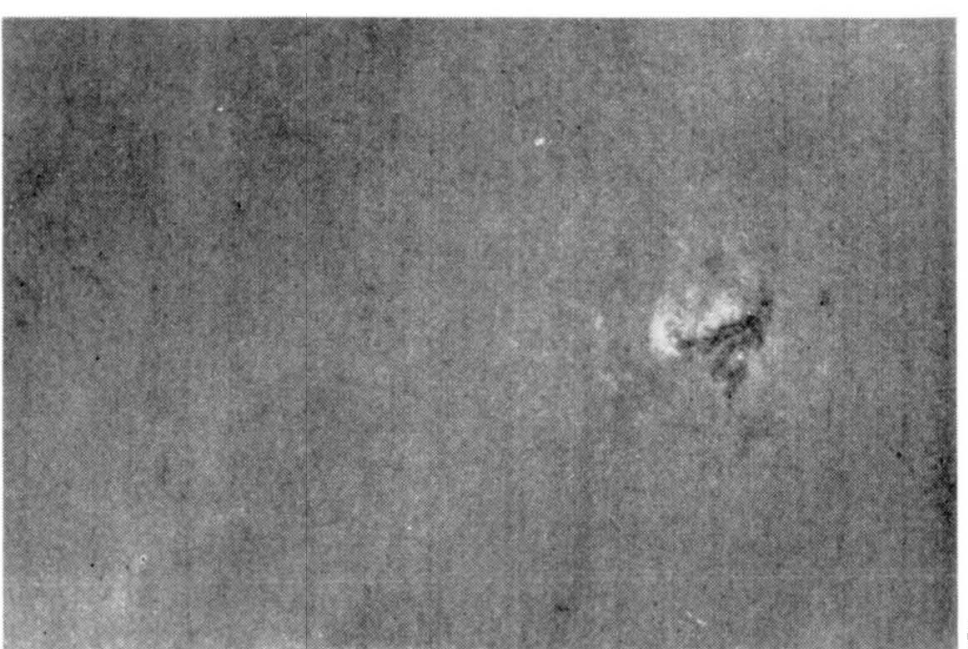

(b)

Fig. 2. (a) Spectroheliogram in the continuum in the Ca I 6103 line. - (b) Cancelled magnetogram by Leighton's method, made by N. Sheeley, Sept. 16, 1430 UT. The field is very complicated, except for the triple spots (light is S polarity). A line of strong N polarity runs through the center of the group, and is marked by the boundary of bright plage in the H-alpha picture (Figure 12) taken shortly afterward. - (c, d) Same for Sept. 20, 1445 UT. The triple spots rotated by about 45 degrees relative to the large spot in these 4 days (mostly between Sept. 16 and 18); the straight line of north polarity is now S shaped and there are strong inclusions of field of opposite sign. Note the open structure of the fields toward the west; this presumably is the reason that the flare waves moved out in this direction. $\mathrm{N}$ top, E right. 


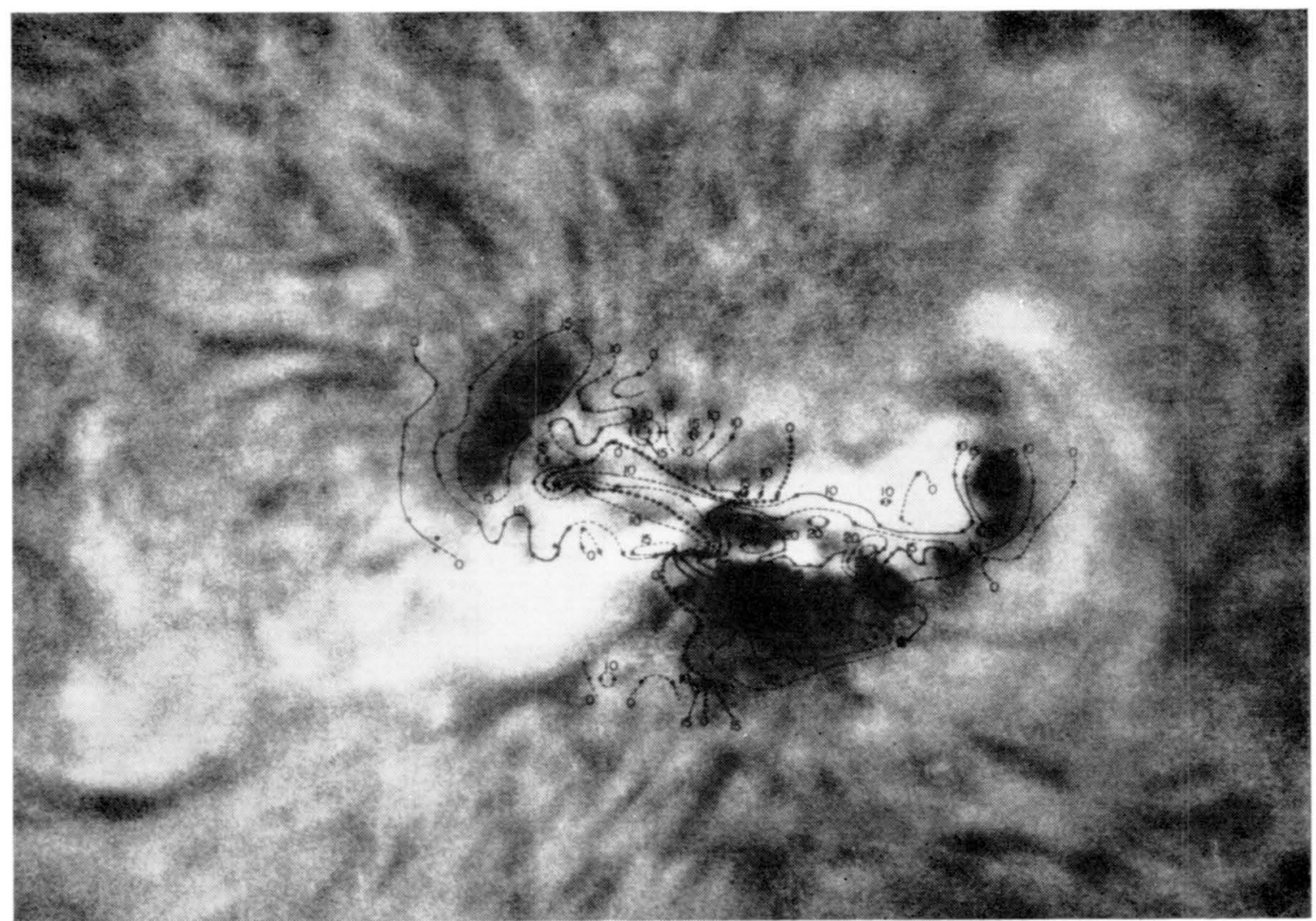

Fig. 3. Contours of longitudinal magnetic field intensity measured by TeSKE, DoDson and Hederman (1964), superposed on our H-alpha picture, Sept. 18. The zero field contour should be extended along the filament to the left. Note that brightening never crosses the zero field contours. $\mathrm{N}$ top, $\mathrm{E}$ right.

(1964) map is shown in Figure 3, superposed on an H-alpha picture. The $\mathrm{N}$ and $\mathrm{W}$ parts of the group show one polarity, the $\mathrm{E}$ and $\mathrm{S}$ the other. A sharp field boundary runs through the center of the group, but there are some inclusions of opposite field. The large sunspots show gray because the magnetograms saturate. On Sept. 20 the structure was much the same, except that the triple spot rotated to the N. There is a complex intertwining of strong fields between the triple spot and the large sunspot, through the remains of the elongated spots of Sept. 18. In Figure 4a we show letter designations for different areas Sept. 17-22; in Figure 4b the same is given for Sept. 23-25. A long "streamer" of S polarity came right up to the large spot and ended near a light bridge across it. This light bridge, which we designate $\mathrm{A}^{\prime}$, appeared on the 17th. A number of flares start with disturbances originating here, moving NE into the bay $\mathrm{G}$. Another region of activity is the intrusion of $\mathrm{N}$ polarity near the triple spot, which also appears on the 18th in the TESKE, Dodson and HEDEMAN (1964) map. This area is marked H in Figure 4a. It is quite clear that SEVERNY's $(1958,1960)$ point on the importance of regions of strong magnetic gradients in flares is correct - on the other hand we must remember that these areas often show bright plages and they are therefore easily brightened by flare disturbance. But cinematography does show that certain pockets were the sources of disturbance waves associated with flares these were the plage area $\mathrm{I}^{\prime}$, which showed medium strength fields of irregular polarity; 
the light bridge $\mathrm{A}^{\prime}$; the intrusion of $\mathrm{N}$ polarity $\mathrm{H}$ near the triple spot, and the area $\mathrm{C}$ just $\mathrm{S}$ of the large spot. Sheeley's magnetogram shows all these regions to have very irregular fields of alternating sign.

Comparison of the $\mathrm{H}$-alpha pictures with the magnetograms is most instructive There is a close correspondence of the $\mathrm{H}$-alpha and magnetic features, as seen ir Figures 2 and 3. A filament extended westward from the central spot; we know suct
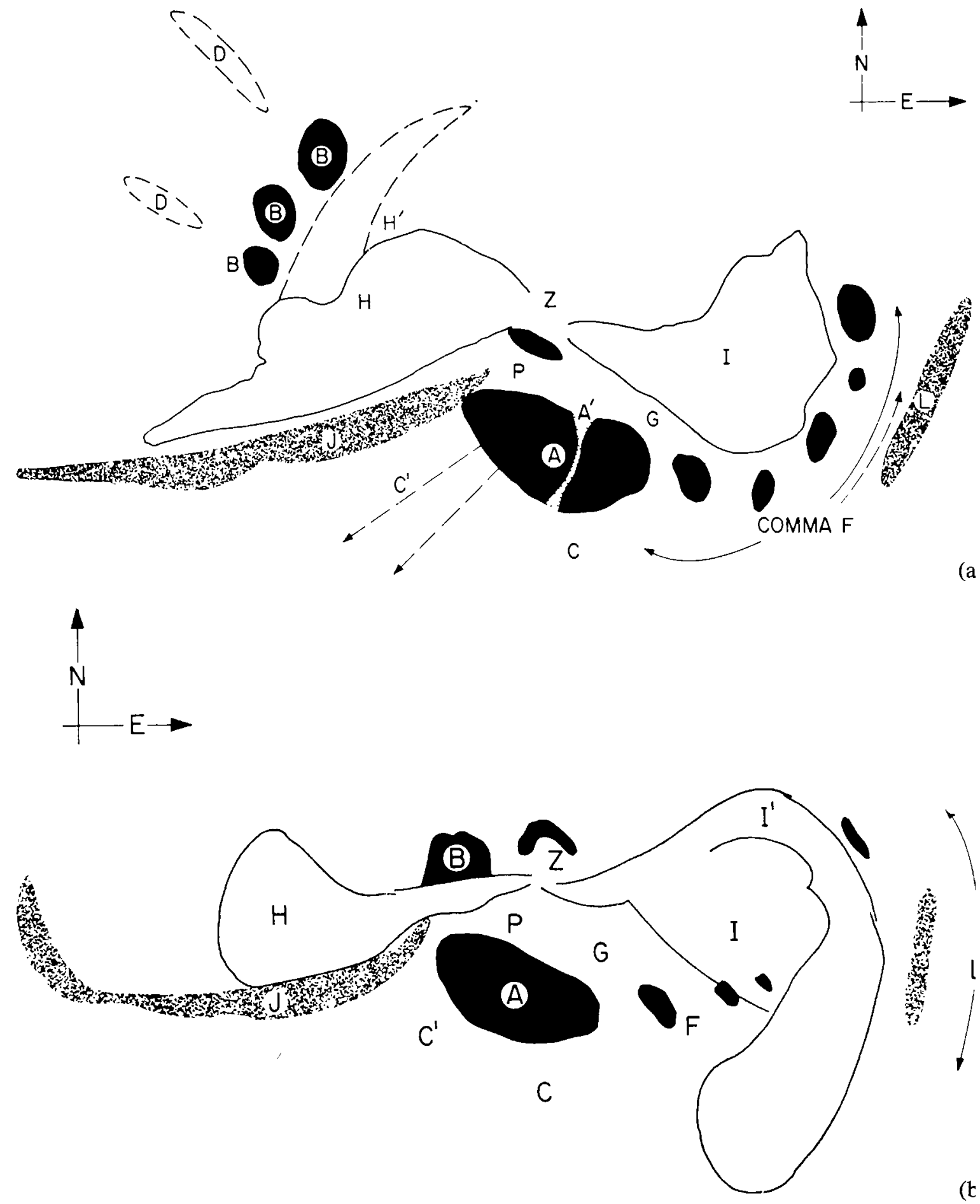

Fig. 4. Drawings indicating areas referred to in text. (a) Sept. 17-22. - (b) Sept. 23-25. 
filaments mark the neutral line from the work of HowARD and HARVEY (1963). This filament joined the zero polarity contour, which wound through the center of the hourglass and out the other side. All of the big flare waves moved out along the neutral line westward along the filament, probably because the field falls off most steeply in that direction. The filament (J) may be followed to the 25 th and forms an important landmark. If flare-connected changes occur, we should see them in $\mathrm{H}$ alpha, but in contrast with Severny's magnetograph results, we never do.

We have tried to identify all the rapid phenomena - flares, surges, and waves occurring in the region during our period of coverage. We have identified the various locations by letter, and tried to compare them with the general structure of the field, to get some insight into the places where flares occur. These letter designations are shown in the drawings Figure 4a for 17-22 Sept. and Figure $4 \mathrm{~b}$ for 24-25 Sept. On the 18th, most of the big flares started in the light bridge area $A^{\prime}$ near the big spot. Most of these flares spread out through the neck of the hourglass $(Z)$ to fill the plage region $\mathrm{H}$ and $\mathrm{I}$, and were accompanied by surface waves traveling westward. There is some evidence that one of the Sept. 18 flares was triggered by a small flare in the neck $Z$, where the steepest field gradients exist. There is rapid traveling of disturbance

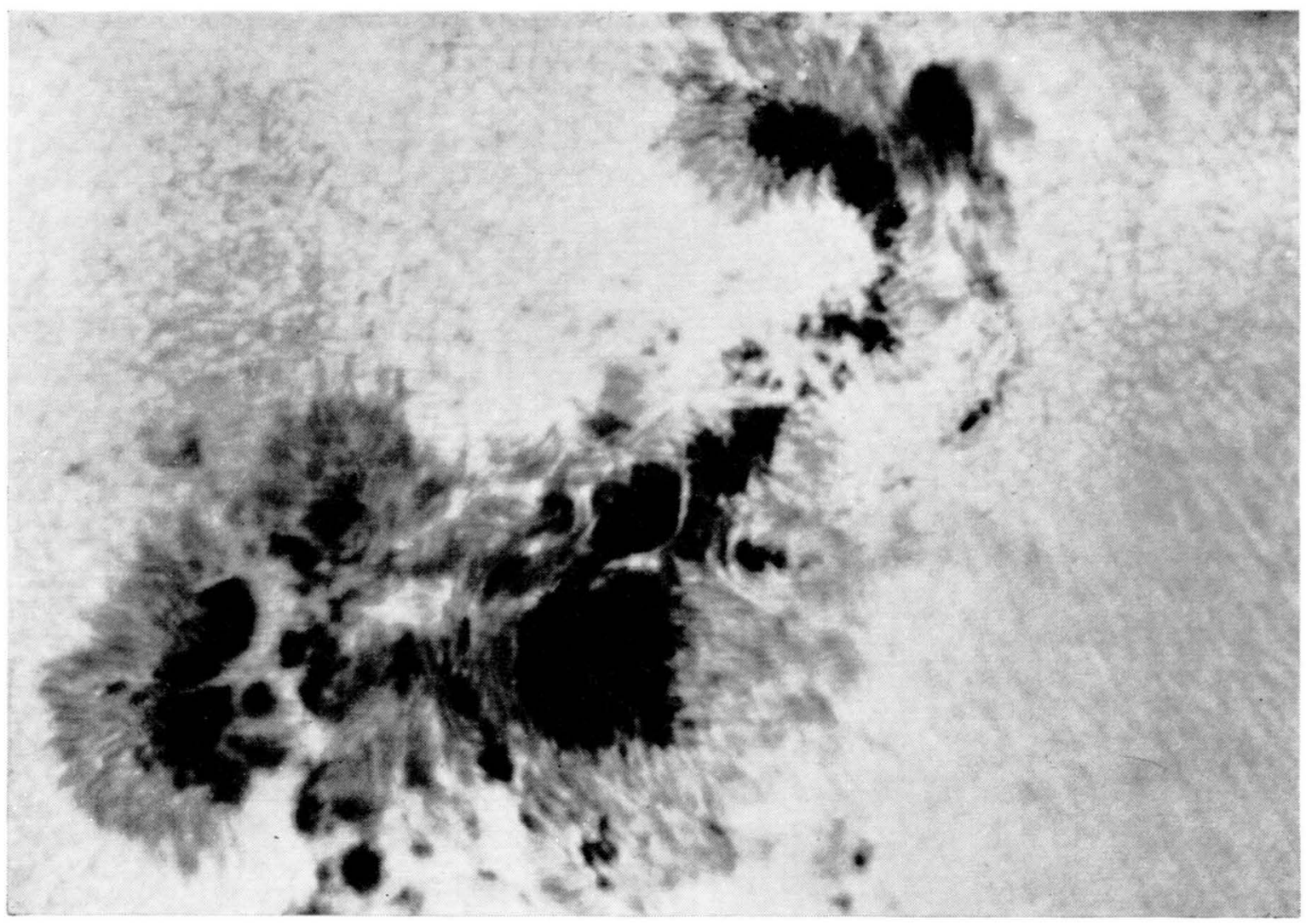

Fig. 5. Sept. 20. White light picture taken by Bumba at Ondřejov Observatory. Only traces of the three elongated spots which were prominent on the 17 th remain, but the granules in this region show alignment on a circular arc around spot $\mathrm{A}$. The comma of spots $\mathrm{F}$ has become greatly elongated in a northeasterly direction. $\mathrm{N}$ upper left, $\mathrm{E}$ upper right. 


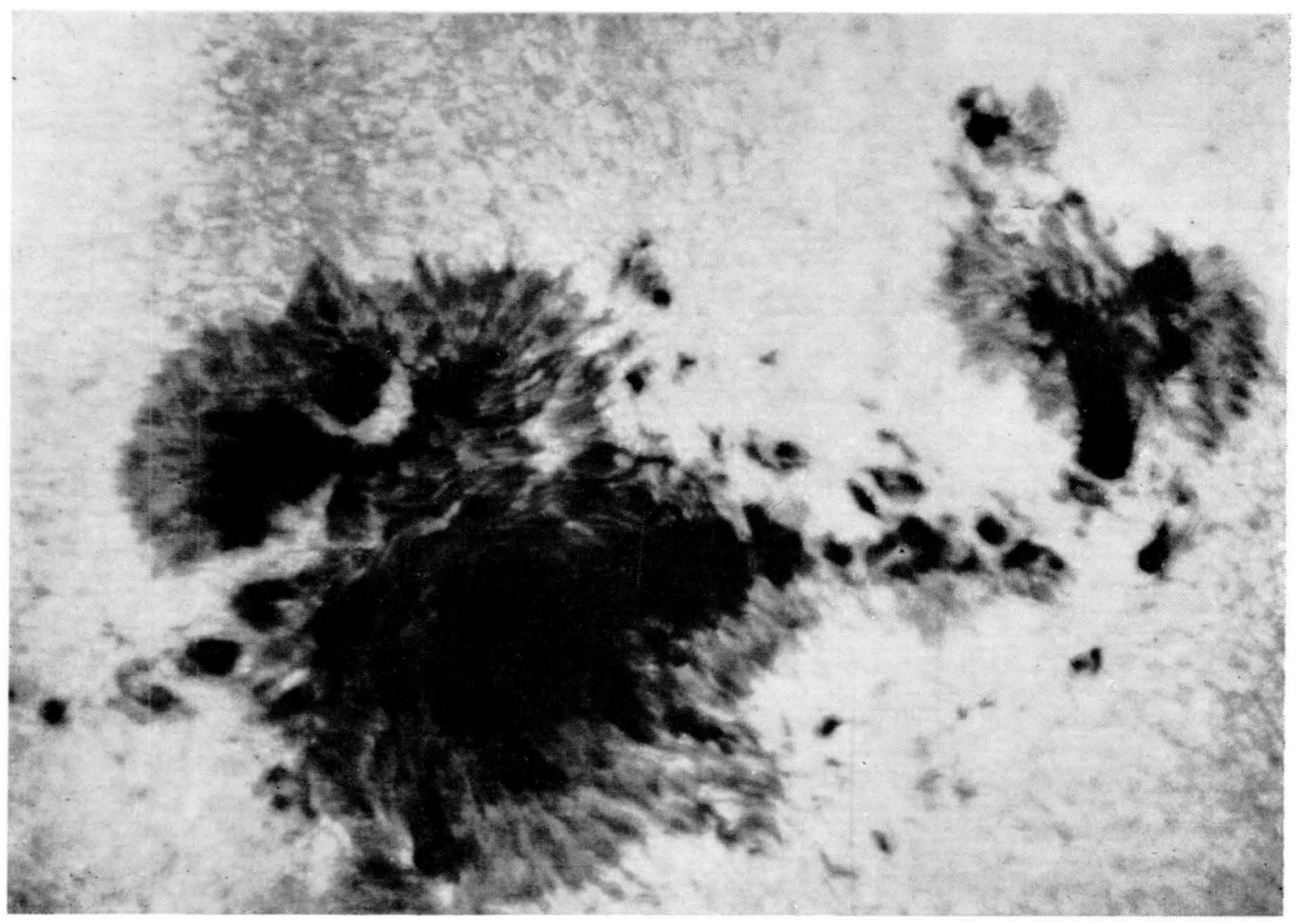

Fig. 6. Sept. 21, 0725.44 UT. White light photograph (Bumba, Ondřejov Observatory). The triple spots B have moved north and somewhat closer to the main spot A. The larger spots in the comma $F$ appear to have broken up into many smaller fragments. The penumbral areas are, in general, larger and more pronounced. The light bridge $\mathrm{A}^{\prime}$ can also be seen. $\mathrm{N}$ top, $\mathrm{E}$ right.

back and forth along the E-W axis of the group through the neck $\mathrm{Z}$ - this occurs every day of observation, but is best marked on the 18th, 19th, and 23rd.

The spot group evolved rapidly after Sept. 18, as shown by Figures 5-8. By the 20 th and 21 st the triple spots had moved in very close to the main spot, forming a single large, complex penumbra, while the following comma of spots stretched even further to the east. After the 20th the bright plage $I^{\prime}$ was on the north side of the following region, and concave to the south. Presumably there is some connection between the rapid evolution and the great flares which occurred on the 18th, 19th, and 20th. Our movies for the 19th show continual violent motion from 1344 to 1822 UT.

Despite the change in the appearance of the group, flares continued to occur in the same places in the distorted coordinate system. There were several explosive flares on the 24th and 25th in the successor, $\mathrm{I}^{\prime}$, to the old comma region and some small ones in the neck $Z$. The surface waves always traveled out through the neck to the west. On the evening of the 24th there was renewed activity at $C$ on the south side of the large spot. Some small spots are seen there in Figure 7. It was here that the series of flares accompanied by type III bursts occurred on the 25th, but many surges had occurred here already on the 17 th. 


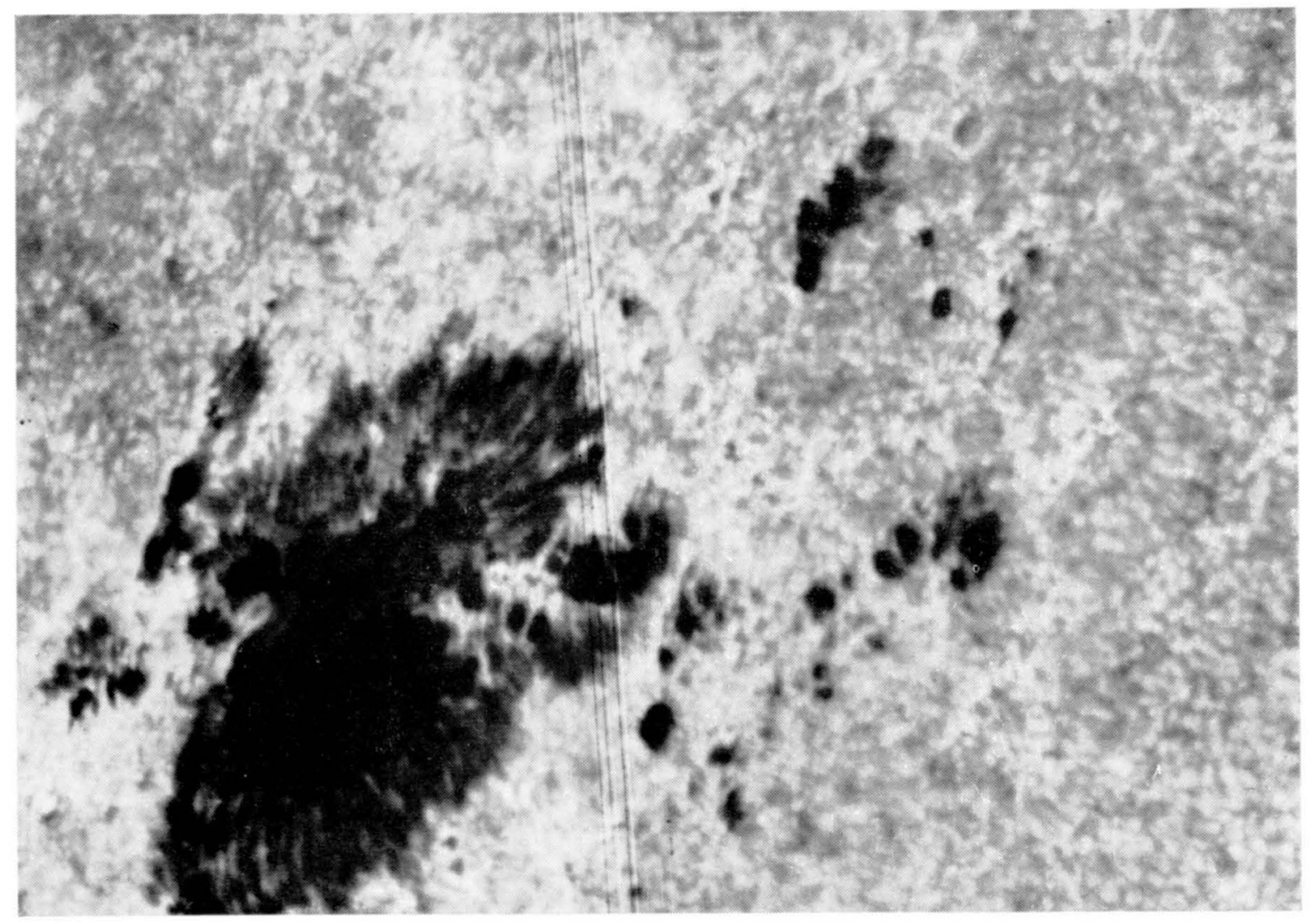

Fig. 7. Sept. 24 (McIntosh, Sacramento Peak). The triple spots B have merged with the large spot A to form a single complex umbra. The comma of spots $F$ is now discernible only as a series of separate small spots stretching in a northeast direction. NE top, SE right.

One interesting result of the persistence of flaring regions is that we can observe similar types of flares near the center of the disk and near the limb. In viewing the pictures, one may easily be deceived into thinking the flares are dissimilar; but we must allow for the fact that we see only a surface plan at the center but a height distribution at the limb. The limb darkening of the background makes fainter features visible, but on the other hand the coarse, irregular structure of the chromosphere and of the active regions obscures many low-lying features near the limb. The sprays seen at $\mathrm{D}$ above the triple spot on the 17 th and 18th are almost certainly far above the surface, and have little connection with the surface features against which they are seen projected.

In our identification of the times of flares, particularly those connected with simultaneous radio events, it must be recognized that many events are rather subtle. Often we may pick out a brightness increase or a morphological change leading up to a flare, but this may not reach flare brightness for some time. So the listed beginning times are somewhat subjective. We concentrate on the beginning times because these have been shown by many authors (MORETON, 1963) to be closely connected with impulsive activity, and our study bears this out (with the exception of flares with delayed flash phases). It should also be remembered that radio and iono- 


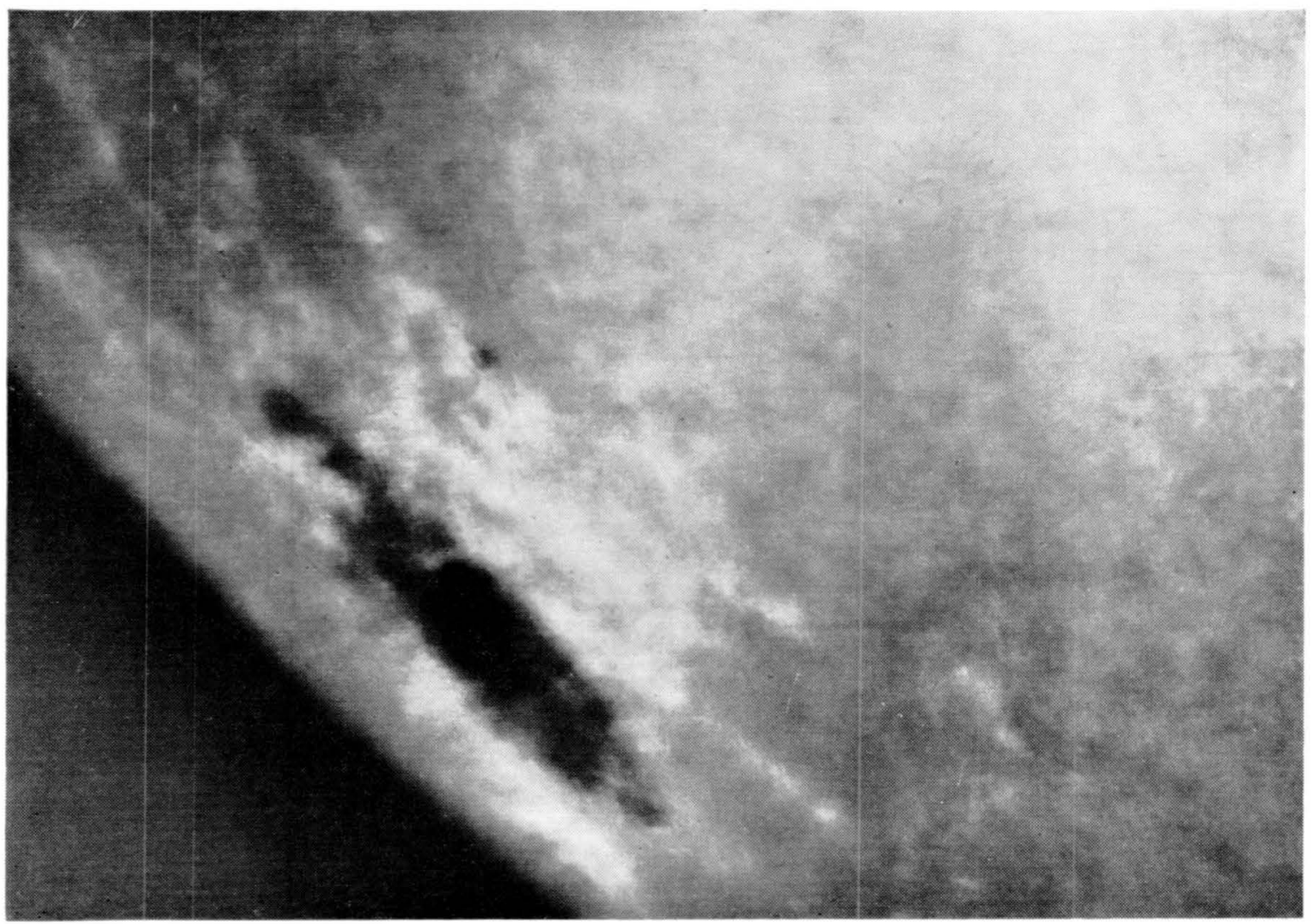

Fig. 8. Sept. 26 (Bumba, Ondřejov Observatory). A single large spot with penumbra is seen. Extensive plage areas are seen in this white light photo. $\mathrm{N}$ left, $\mathrm{E}$ top.

spheric coverage are not always complete, especially after 2000 UT, and that most of the higher frequency records are not sensitive to small bursts. We found Dr. J. W. Warwick's Boulder $15-40 \mathrm{Mc} / \mathrm{s}$ data most useful (except during noise storms) because of their great sensitivity.

Correlation of the smaller events with radio bursts is difficult, because there was a continual noise storm at meter wavelengths during this period. Limb darkening eliminated this interference to some extent on the $25 \mathrm{th}$, and we were able to make detailed comparisons.

\section{Detailed Description}

We give below a detailed description of the events noted on our films for this period compared with ionospheric and radio data. Only the extremely small events (which are very frequent) are omitted. We did not measure flare areas or attribute importance to them, but we include the measured importance in parentheses if a flare was reported by one of the regular flare patrol stations. For ionospheric data, SFD = sudden frequency deviation; SPA = sudden phase anomaly; SLSWF $=$ slow short wave fadeout; SEA = sudden enhancement of atmospherics; SES = sudden enhancement of spherics. (Classification of $2800 \mathrm{Mc}$ bursts is given in Covington's system.) We give the beginning of each event unless otherwise specified. The data principally comes 
from the Solar-Geophysical Data of CRPL. In the tables, events not observed by us are in parentheses.

The active region first appeared over the east limb of the sun on 13 September. Our observations of the region above the limb were made with the disk occulted.

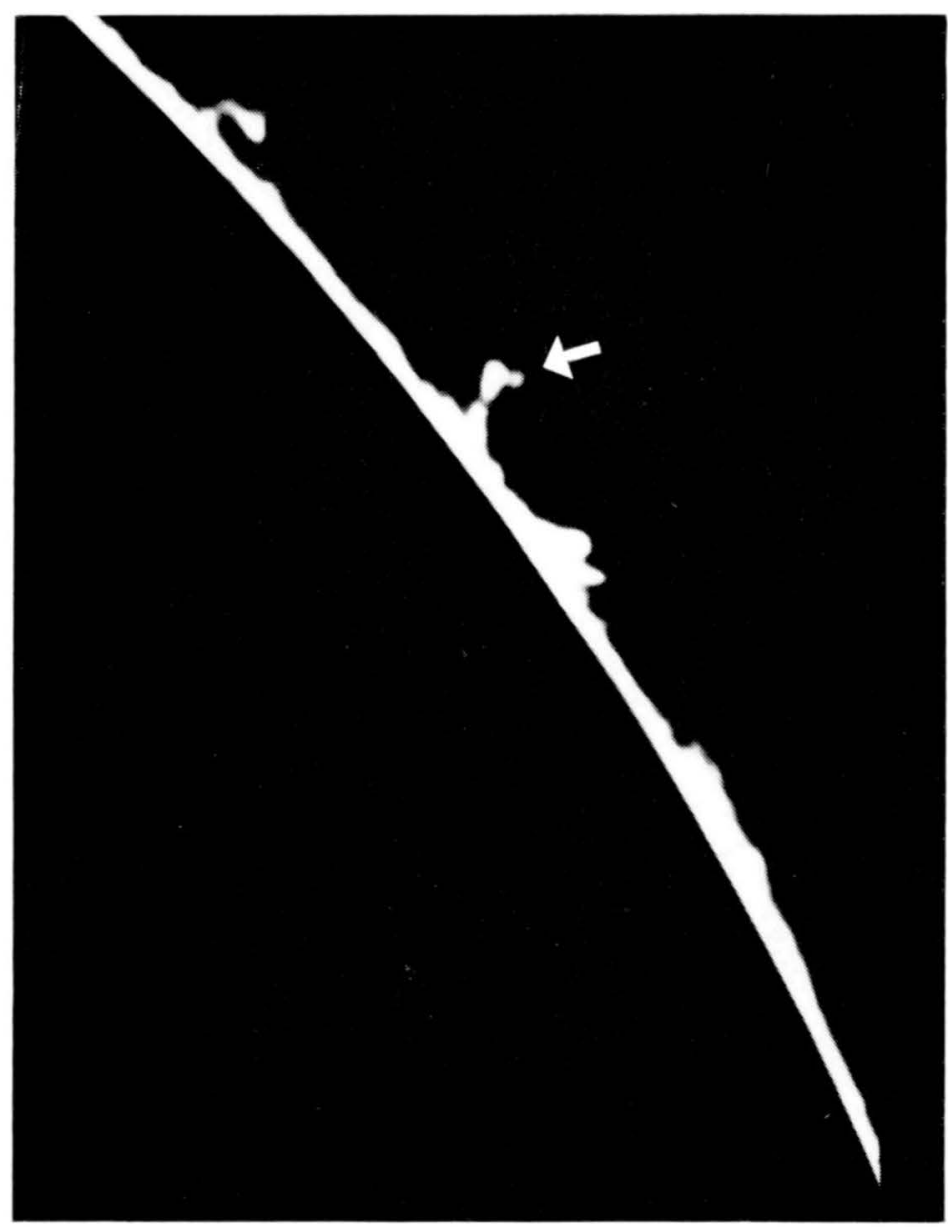

Fig. 9. Sept. 13, 1545 UT. Surges, loops and sprays such as this one (arrow) were observed as the active region appeared on the east limb.

Several events were observed in the short observing period that day, including a fast spray at 1545 (Figure 9), which produced an ionospheric effect and a bright, rapidly changing explosive ball at 1638 UT. The 1656 UT event which gave a simple 3 burst at $2800 \mathrm{Mc}$ looked like a brightening of exisiing loops and may have been a purely thermal radio event. There were small surges and loops all day.

We had no observations on 14-15-16 Sept., but the development of the region is shown by the spectroheliograms obtained at Mt. Wilson (Figures 10,11, 12). The region was preceded by a large dark filament dividing the $S$ polarity of the preceding part of the group from the North polarity of the extensive unipolar region to the North. A flare is shown in progress in the picture on the 16th (Figure 12) - it is generally similar to those on later days. 
TABLE I

13 September 1963. Observation period: $1346.15-1704.15$ UT

Disk occulted, true location not available

\begin{tabular}{ll}
\hline Time (UT) & \multicolumn{1}{c}{ Event } \\
\hline 1509 & Surge ((1-) flare, 1506-11-24.) \\
1545 & Flare Spray (SFD 1540-4.) (Figure 9.) \\
& (Flare (1), 1532-43-50.) \\
1625 & Surge, followed by loops. \\
1638 & (Explosive flare (1-), 1640-52-00.) \\
1656 & In situ flare above limb ((1-), 1701-3-9.) \\
1657.5 & (2800 Mc Burst, 1 simple 1.) \\
\hline
\end{tabular}

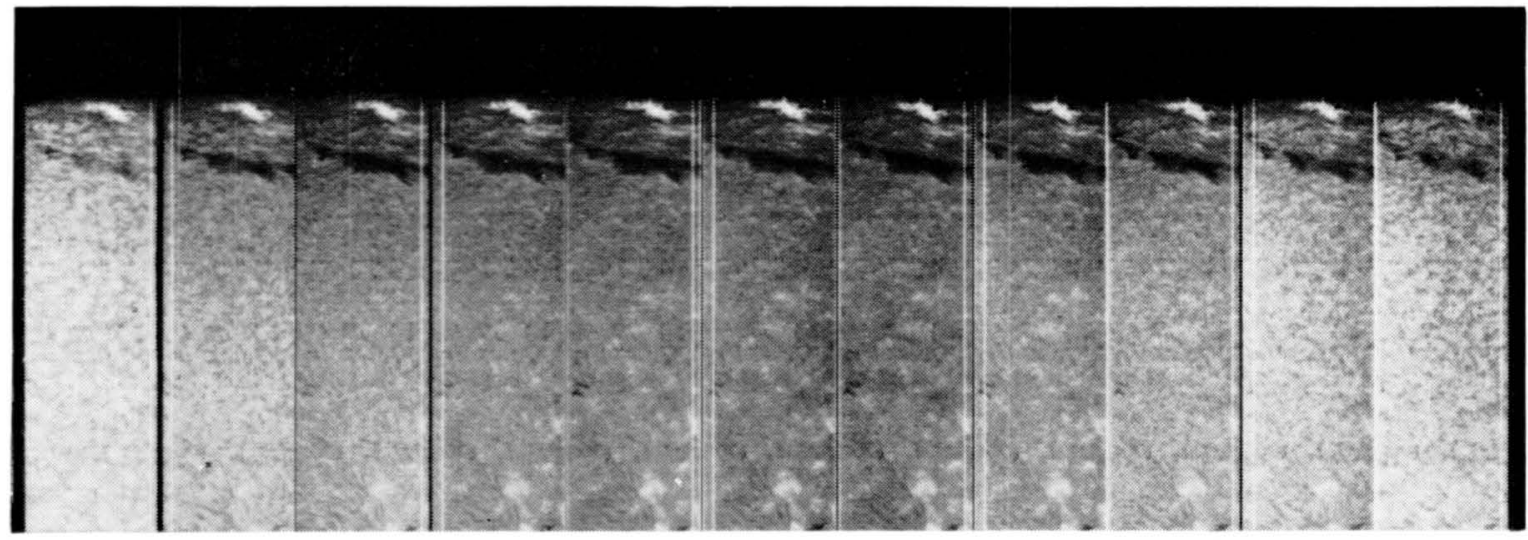

Fig. 10. 1426 to 1433 UT. Series of H-alpha spectroheliograms by Sheeley (Mt. Wilson) for September 14, showing the structure of the region in different wavelengths. Scans start at $-0.35 \AA$ (right) and move through the line center, $0.07 \AA /$ step. E top, N left.

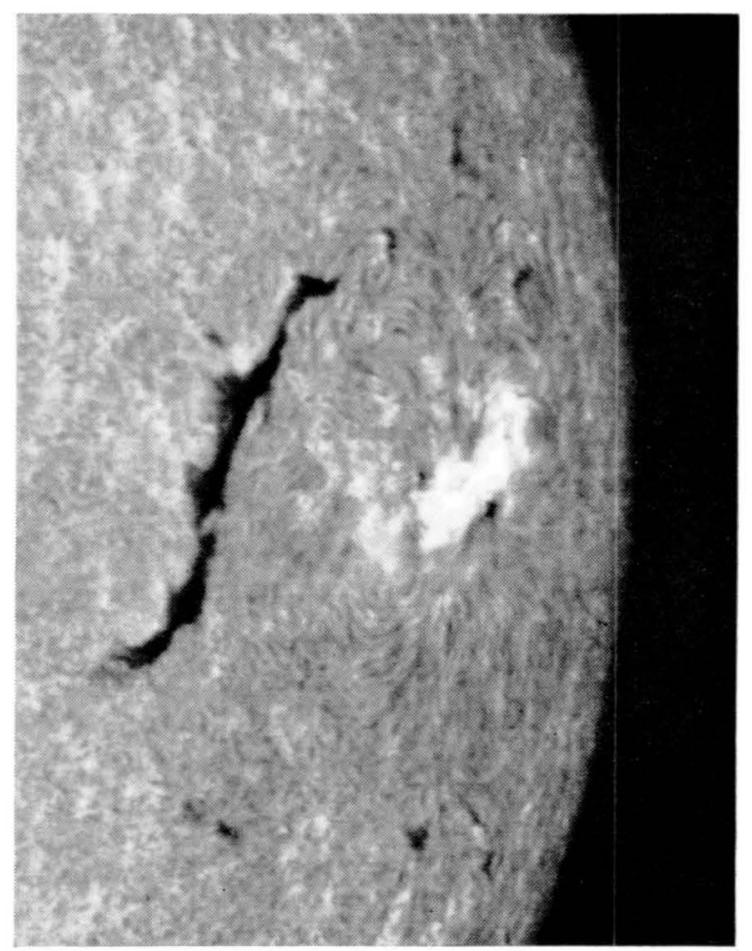

Fig. 11. H-alpha spectroheliogram by Sheeley (Mt. Wilson) for Sept. 15. N top, E right. 


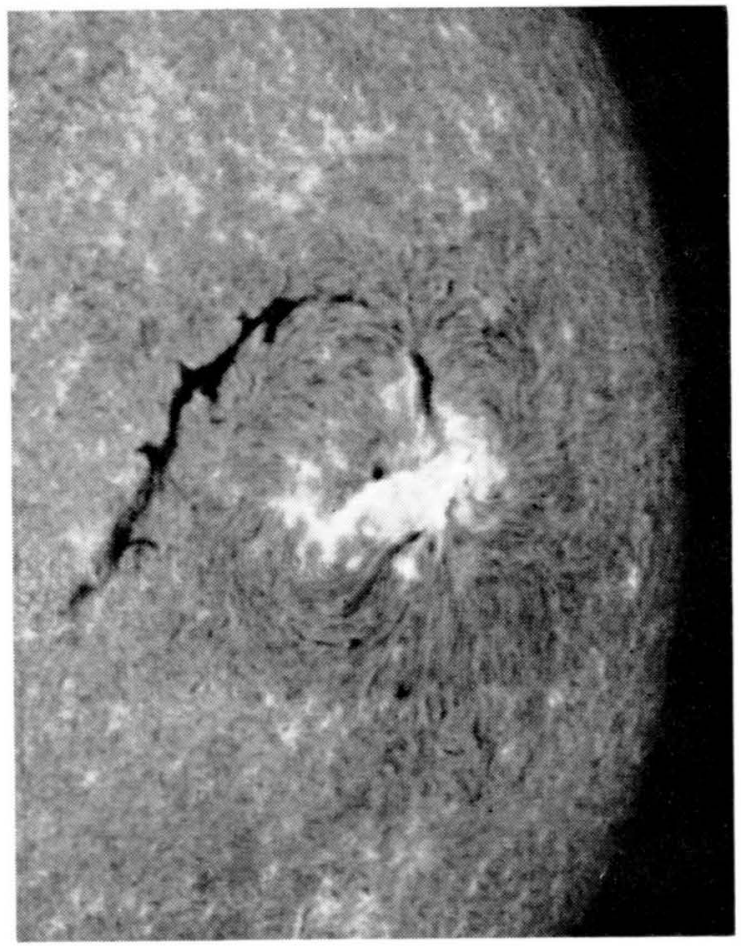

Fig. 12. Same for Sept. 16, showing a flare in progress with characteristic westward development. 1521 UT.

TABLE II

17 September 1963. Observation period: 1413.00-1650.00 UT

\begin{tabular}{|c|c|c|}
\hline Location & Time (UT) & Event \\
\hline & & Continual flares and surging all over the group. \\
\hline $\mathrm{C}^{\prime}$ & 1414 & Dark surge. \\
\hline G & 1416 & Flare. (Figure 1a, b.) \\
\hline $\mathrm{D}$ & 1420 & First large spray. Probably high above surface. \\
\hline $\mathrm{C}^{\prime}, \mathrm{G}$ & 1427 & $\begin{array}{l}\text { Wave from returning surge } C \text { of } 1414 \mathrm{UT} \text { travels around spot, producing } \\
\text { flare brightening }(1432,(1-)) \text { along trajectory from } C^{\prime} \text { to } G \text {, and re- } \\
\text { peating as surge from } C^{\prime} \text { at } 1438 \text {. (Figure } 13 \mathrm{a}, \mathrm{b}, \mathrm{c} \text {.) }(167 \mathrm{Mc} \text { burst }(\mathrm{BoN}) \text {, } \\
1429-1517 \text {, Type } 1 \text {, Int. 2.) (IIIG burst, 1449-52 UT, Int. 2, (F.D.).) }\end{array}$ \\
\hline $\mathrm{C}$ & 1500 & Small flare and dark surge. \\
\hline $\mathbf{H}$ & 1508 & Flare. \\
\hline $\mathrm{C}$ & 1513 & $\begin{array}{l}\text { Bright flash (1-) and long dark surge. This region shows continual small } \\
\text { brightenings and surges. }\end{array}$ \\
\hline & $1515-1517$ & (IIIG burst, Int. 3, (F.D.).) \\
\hline & 1529 & (III burst, beginning of noise storm, simultaneous with) \\
\hline $\mathbf{H}$ & $\begin{array}{l}1530 \\
1552\end{array}$ & $\begin{array}{l}\text { Bright wave from flare at } \mathrm{H} \text { through neck from west to east. } \\
\text { (3 simple } 3,2800 \mathrm{Mc} \text {, Int. 1.5.) }\end{array}$ \\
\hline $\mathrm{F}$ & 1554 & $\begin{array}{l}\text { Bright flash (1-) duration } 6 \text { minutes. Moves along dark whorl around } \\
\text { east of comma (L.) }\end{array}$ \\
\hline $\mathrm{C}$ & 1560 & Dark surge. \\
\hline G & 1605 & Brightening moves back and forth in bay. \\
\hline $\mathbf{D}$ & 1613 & Second spray from brightening above triple spots. \\
\hline F & 1634 & Repeat of 1554 flare (1-). \\
\hline
\end{tabular}


Table II summarizes the events of 17 September; positions correspond to thos given on Figure 4a. The day was characterized by continual surge, spray and flast activity. A remarkable repeating surge occurred at 1414 UT (Figures 13 and 1b) Upon return of the material which surged southwest from $C^{\prime}$ (Figure 13a) at 1414 UT a flare occurred at $\mathbf{C}^{\prime}$ (Figure 13b) at the bottom of the surge, starting a second surge (Figure 13c); at the same time the wave from the falling surge traveled across the region, and a small flare occurred at $\mathrm{G}$. This is the best evidence we have seen of the importance of the "splash" produced by a returning surge. A spray at D, northwes of the triple spot, at 1420 UT also appeared to be associated with this activity Activity began in the lower region of the group with a bright wave through the neck $\mathrm{Z}$ at 1530 UT. Simultaneous radio and optical activity occurred many times on thi: day: $1429,1449,1515-1517,1529$ and 1613 . The radio bursts always occurred befor or at the beginning of the optical flare. The spray at 1613 was similar to that at 1420 and two more sprays homologous to those occurred on the 18th. All these spray: probably occurred high above the surface and are seen in projection against the are: $\mathrm{D}$, northwest of the triple spots.

The release of energy by material falling to the surface has been discussed before The 1414 UT et seq. activity is a good example of this phenomenon.

We were particularly interested in studying 18 September because (1) fine film: of flare activity were available for this day, and (2) the TeSKe, Dodson and HeDEMAI (1964) magnetic map (Figure 3) was made on this day and therefore comparisor could be made with the $\mathrm{H}$-alpha photos. We could check the location of flare activit: with respect to the zero-gauss longitudinal field contour and the region of steepes gradient. The most prominent features of the magnetic field map are a region of stron field gradient at $\mathrm{Z}$, to the north of the spot, and a long loop in the neutral line ex tending from the large spot NW toward the triple spot. The inside of the long loop turned out to be devoid of activity; in fact the area inside this loop as seen in Figure: was always dark but some flares began between it and the triple spot. The region o steep gradient $Z$ showed many small flares. It seems a general characteristic that plagr (and flare) brightening only appears between the neutral line and the nearest sunspots This gives large regions with two rows of spots of opposite polatity a characteristir hourglass shape, the sides of the hourglass being the two rows of spots and the neutral line. In late stages the hourglass evolves into the well-known "2-strand" structure.

There are two points of minor uncertainty in the McMath magnetic field map First, there was a prominent active region filament at $J$ which curved into a point $(P$. just $\mathrm{N}$ of the large spot, separating it from the adjacent, smaller spot. It is well established (HowARD and HARVEY, 1963) that filaments mark the boundary betweer fields of opposite polarity. Therefore the filament, (J) designates this boundary. The McMath map does not show this boundary, probably because there are not man! measurements in the region of the filament. The Mt. Wilson drawings show a spo of opposite polarity just $\mathrm{N}$ of the large spot. Bumba's white light photographs as wel as our $\mathrm{H}$-alpha photographs show extremely complex structure in the large penumbra 


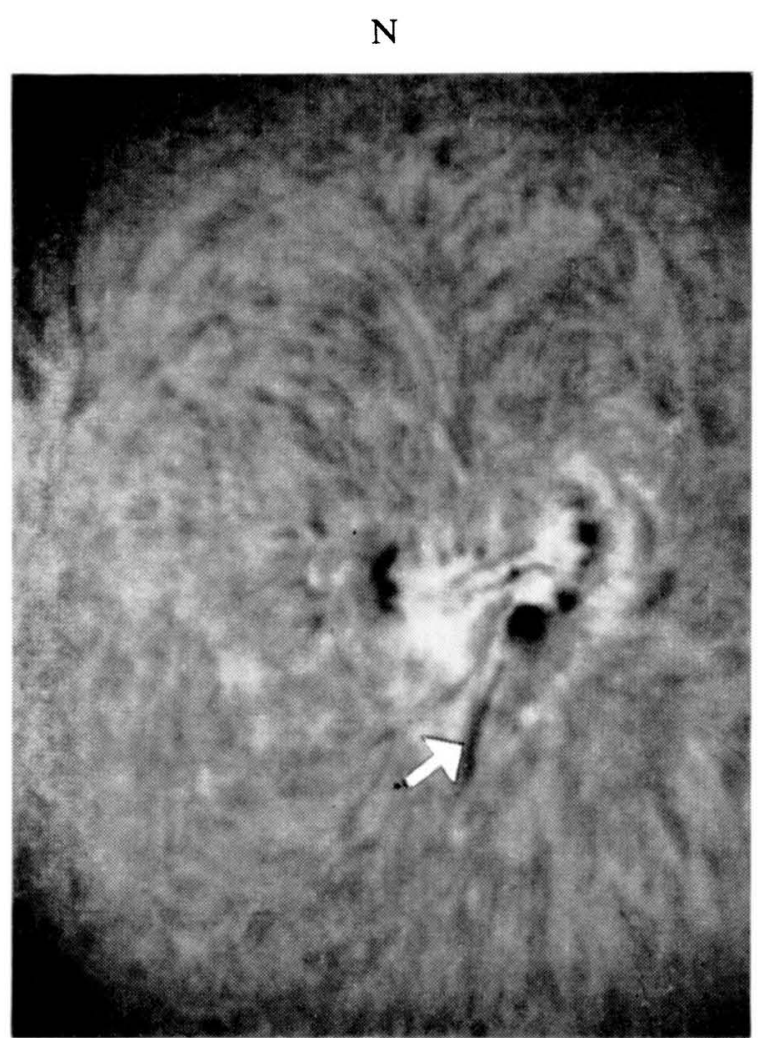

(a)

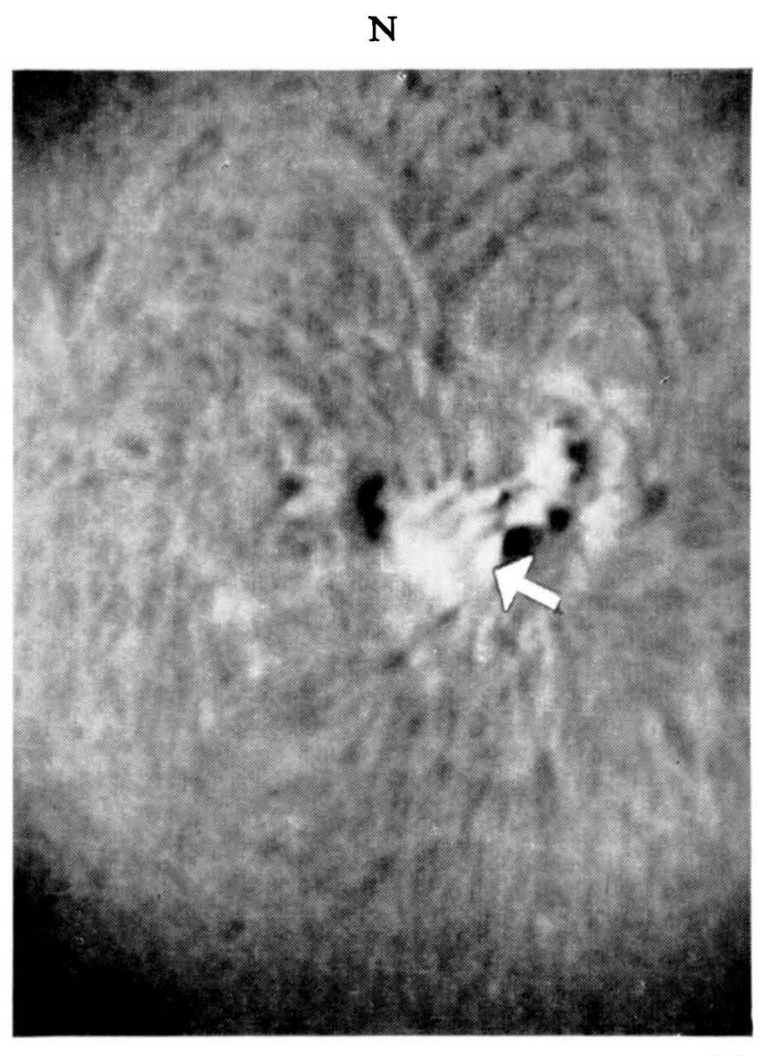

(b)

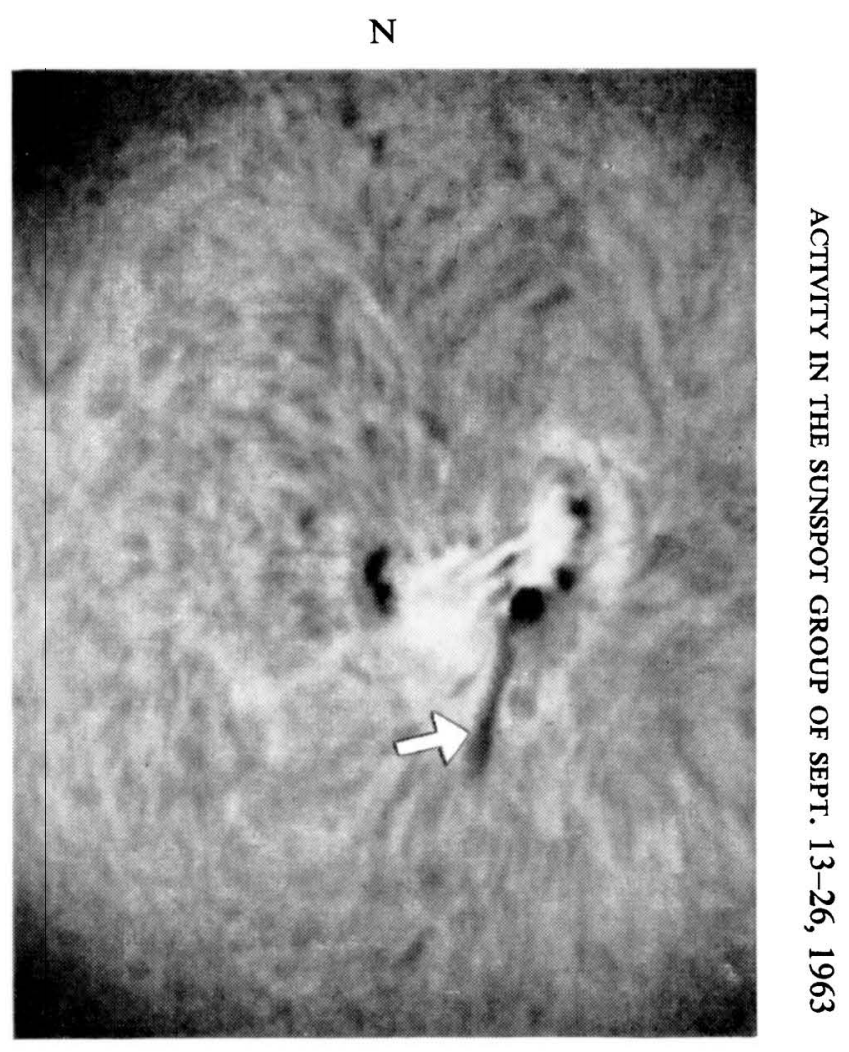

(c)

Fig. 13. Sept. 17. (a) 1417 UT. First surge to southwest from $C^{\prime}$ followed upon its return by (b) flare at 1434 UT and (c) a second surge and flare at $\mathrm{G}$ at 1448 UT. Arrows show each point of interest. 
TABLE III

18 September 1963. Observation period: $1333.00-0059.00$ UT

\begin{tabular}{|c|c|c|}
\hline Location & Time (UT) & Event \\
\hline$A^{\prime}$ or $\mathbf{P}$ & 1344 & Brightening starts. \\
\hline $\mathrm{D}$ & $1357-1416$ & $\begin{array}{l}\text { First spray at } D \text {, north of triple spots. Simultaneous with those shown is } \\
\text { Figure } 14 a, b \text {. }\end{array}$ \\
\hline $\mathrm{Z}$ & 1357 & Small flare in neck $\mathrm{Z} ;(\mathrm{X}$-ray burst at 1356.$)$ \\
\hline $\mathrm{H}$ & 1354 & Flare. \\
\hline G & 1402 & $\begin{array}{l}\text { Start of Class } 2 \text { flare with gradual brightening in G. } \\
\text { (SLSWF 1405-23-1515.) } \\
\text { (SFD 1413-16.) }\end{array}$ \\
\hline All over & 1413 & $\begin{array}{l}\text { Rapid (less than } 1 \text { min.) rise to brightness. Probably starts from necl } \\
\text { and then fills entire hourglass. ( } 2800 \mathrm{Mc} \text { burst.) Figure } 14 \mathrm{c}, \mathrm{d} \text {. }\end{array}$ \\
\hline $\mathrm{D}$ & $1414-1434$ & Second spray. \\
\hline $\mathbf{J}, \mathbf{C}^{\prime}$ & & $\begin{array}{l}\text { Continual brightening beside filament } \mathrm{J} \text { and motion of same. } \\
\text { Continual small flares and surges at } \mathbf{C}^{\prime} \text {. }\end{array}$ \\
\hline \multirow[t]{3}{*}{ G } & 1531 & $\begin{array}{l}\text { Small flare (1-) spreads from } A^{\prime} \text { into G. (Weak type III. Radio storn } \\
\text { all day (Sydney).) }\end{array}$ \\
\hline & 1534 & (Intense type III.) \\
\hline & 1557 & (Intense type III.) \\
\hline \multirow[t]{2}{*}{$\mathbf{Z}$} & 1600 & $\begin{array}{l}\text { Flare }(1-) \text { spreads from both sides of neck } Z \text {, fills hourglass, but } Z \\
\text { remains unbrightened. }\end{array}$ \\
\hline & 1612,1619 & (Intense type III.) \\
\hline G & 1700 & $\begin{array}{l}\text { Rapid flare (1 min. rise) clearly comes out of light bridge } A^{\prime} \text {, fills } \mathrm{G} \text { and } \mathrm{I} \\
\text { (Weak type III.) (SFD (10) } 1659-00-02 \text {.) Figure } 15 \mathrm{a}, \mathrm{b} \text {. }\end{array}$ \\
\hline \multirow[t]{3}{*}{$\mathbf{J}$} & 1700 & $\begin{array}{l}\text { Flash and wave along filament } \mathbf{J}(1-) \text {; probably triggered by flash on the } \\
\mathrm{N} \text { side of H. (Strong type III.) (Figure 15.) }\end{array}$ \\
\hline & 1710 & (Strong type III.) \\
\hline & 1713 & (Strong type III.) \\
\hline $\mathbf{J}$ & $\begin{array}{l}1857 \\
2045\end{array}$ & $\begin{array}{l}\text { Flare (1-) NE of filament J. } \\
\text { (Continual type III bursts.) } \\
\text { (Sydney 2216-19G (I).) Clouded out, 1911-1945, 2104-2130. }\end{array}$ \\
\hline \multirow[t]{2}{*}{ G } & 2130 & $\begin{array}{l}\text { Flare at G. (Strong type III's.) } \\
(2132-54 \mathrm{G} \text { (I) Sydney.) } \\
(2130-3-9 \text { SFD (04).) } \\
(2130-2400 \text { III Sydney.) }\end{array}$ \\
\hline & 2131 & (Group of bursts, Hawaii and Sydney.) \\
\hline $\mathrm{D}$ & 2141 & Spray. \\
\hline $\mathbf{B}$ & 2143 & Flare along SE side of triple spot enlarges, brightens (Figure 16a-d.) \\
\hline A & 2215 & $\begin{array}{l}\text { Flare from } \mathrm{G} \text { begins to cross umbra near light bridge } \mathrm{A}^{\prime} \text {, but at } 45^{\circ} \text { angle } \\
\text { to same (unfortunately). (2231-2-4 SFD (03).) }\end{array}$ \\
\hline B & 2244 & Flare begins crossing first of triple spots. \\
\hline A & 2248 & Flare (1) reaches far side of large spot. \\
\hline \multirow[t]{3}{*}{ B } & 2303 & First of triple spots totally covered, second partially covered. \\
\hline & 2322 & Flare assumes 2-strand structure, covering both row of spots. \\
\hline & 2330 & (Radio continuum becomes much more intense to sunset.) \\
\hline
\end{tabular}

which may not have been resolved in the McMath map. The neutral line must have wound between the long sunspots in a complicated way. However the large scale magnetic structure is fairly consistent with the other data.

The overall structure of the flares in the region clearly depends on the magnetic 
(a)
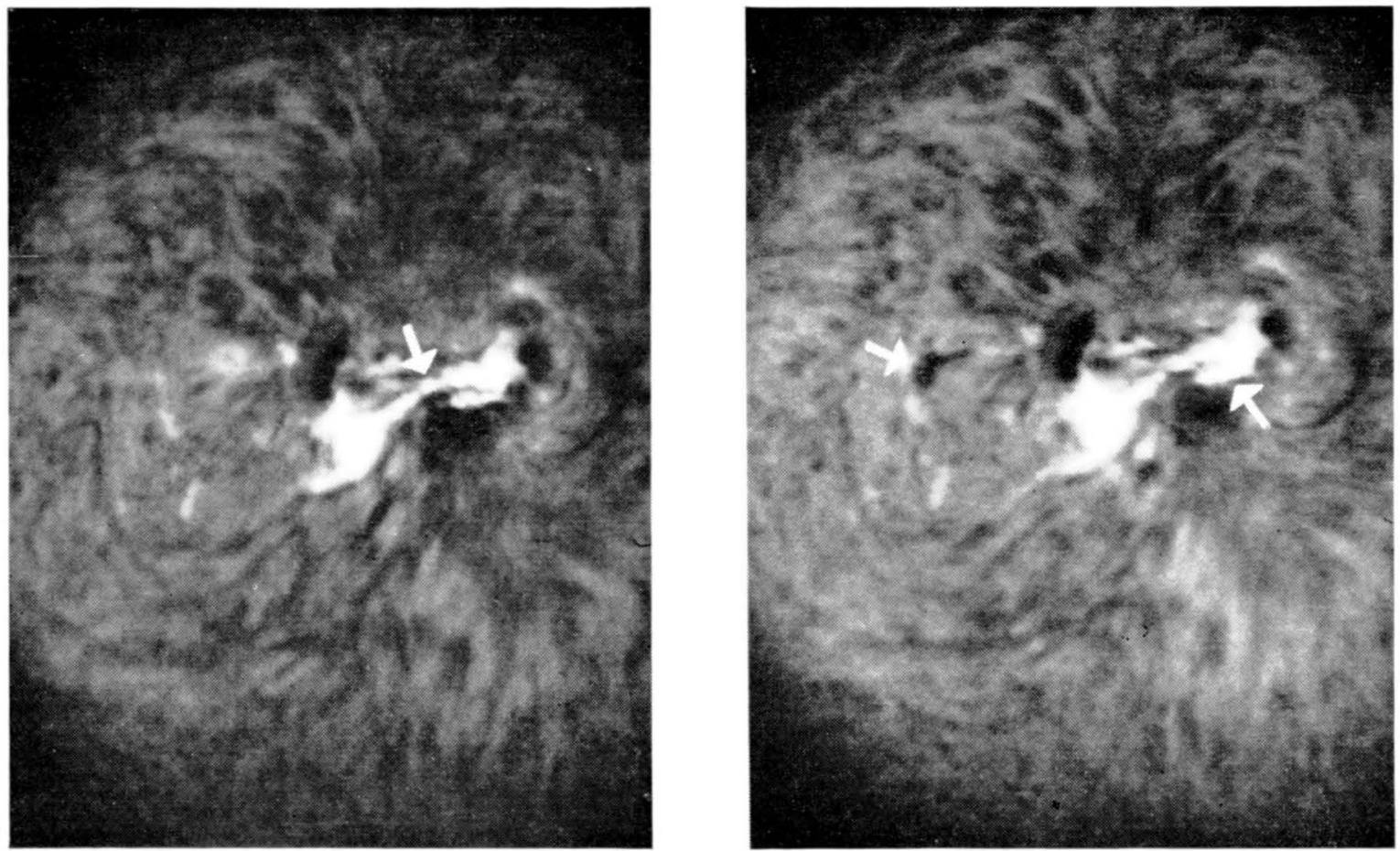

(b)
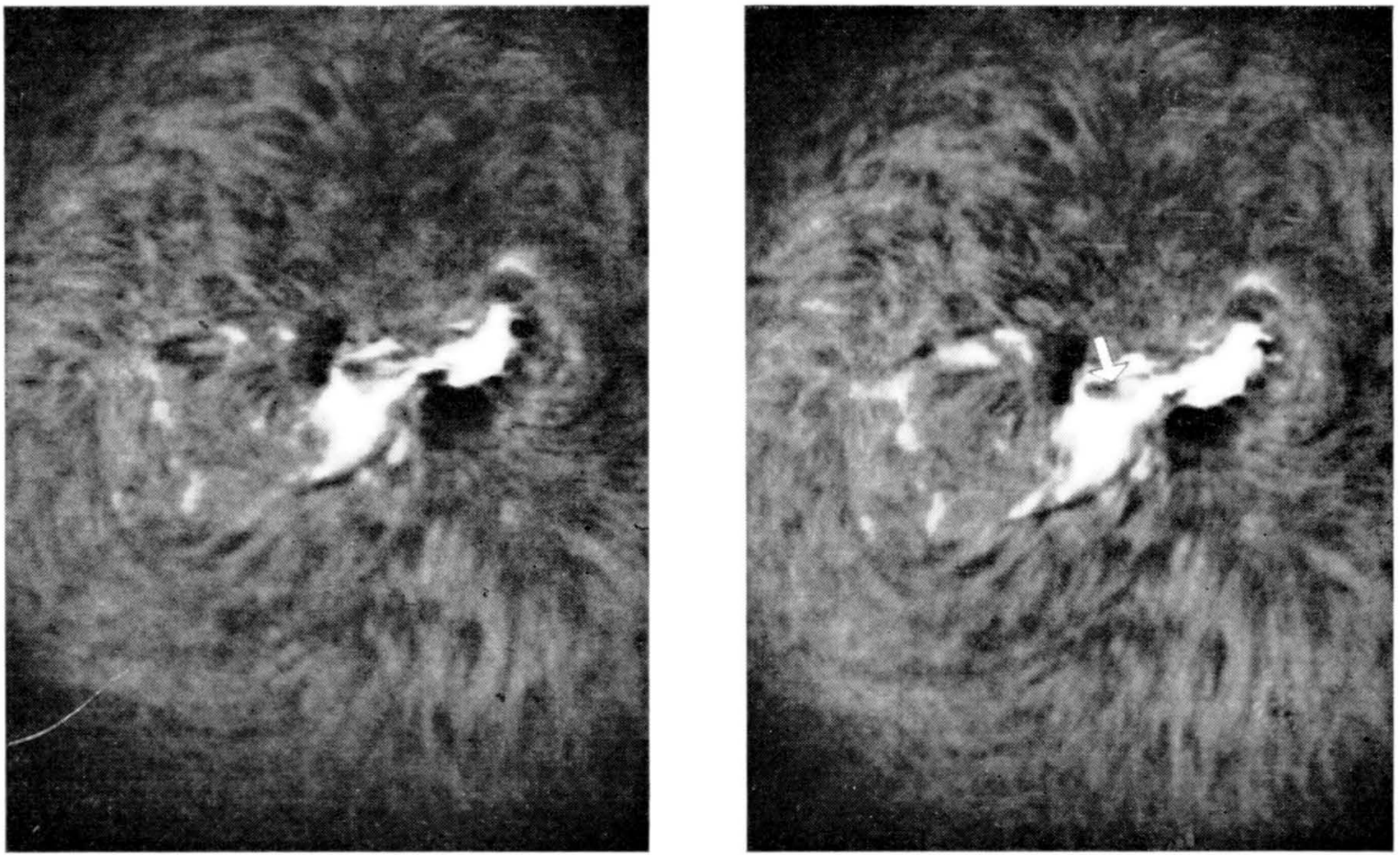

(d)

Fig. 14. Sept. 18. (a) 1358 UT. Small brightening in neck region $\mathrm{Z}$ (arrow); spray at $\mathrm{D}$ begins above triple spot. - (b) 1400 UT. Spray fully developed and dark (arrow); brightening spreads through the bay of flares (I). This is the beginning of the Class 2 flare. - (c) 1413 UT. Flash phase. Rapid spread of brightness through hourglass. - (d) 1418 UT. Maximum of flare. In this case region along the filament $\mathrm{J}$ does not brighten, as in later big flares. 
field structure, which, as outlined in $\mathrm{H}$-alpha, did not change significantly in the cours of the day. The large flares showed at maximum brightness the characteristic hourglas shape (part of which may have been due to the superposition on the relatively darl sunspots) which we have already noted. The west portion $\mathrm{H}$ was between the filamen and the triple spots of $\mathrm{N}$ polarity in the NW and the east portion I was a "bay o flares" between the neutral line and the comma-like chain of spots (of S polarity) $\mathrm{F}$ The northeast boundary of this bay I was also bounded by the neutral line loo] extending from the main spot to the triple spots. The large bright regions of the hour glass were connected by the neck $Z$, where field gradients were the greatest. Ther were also bright strands connecting the glasses through the point $P$ to which th filament pointed, which must also have been a neutral line, separated from $\mathrm{Z}$ by : long sunspot. We must emphasize that the configuration of a flare at maximum are: and brightness may have no relation whatever to the configuration in which the flar energy is released - it may only be the locus where this energy is delivered to th surrounding chromosphere. An alternative possibility is that this is the locus of un stable regions where energy release is called forth by a wave of excitation from th seat of the flare.

It is interesting that the region of flare brightening extended along the $\mathrm{N}$ polarit side of the filament for a considerable distance outside the group. This is particularl: true of the 2215 UT flare, which was almost identical with the Sept. 20 flare recorder by Lockheed.

There were three major flares on 18 September. An initial spray occurred at 135 UT homologous with those of the 17 th. A small flare in the neck region (Z), i.e., th region of steepest gradient, triggered a flare (Class 1) at 1413 UT (Figure 14). Afte a flash at 1404 UT, a disturbance moved out from this neck region in both directions A brightening also appeared (1407 UT) south of G inside the comma of spots an spread to the north across the tops of these spots. At 1413 UT a brightening in th glass $\mathrm{H}$ spread around the loop in the neutral line. and one minute later a bright wav passed through the neck $\mathrm{Z}$ from east to west and the entire flare brightened sharpl in less than $1 \mathrm{~min}$. (flash phase). Simultaneously there was a $2800 \mathrm{Mc} / \mathrm{sec}$ burst an SFD. Also at 1414 UT there was a small brightening in the region G; again th brightening was preceded by some activity in the neck.

Later in the day a small bright flash at $\mathrm{H}^{\prime}$ may have been the trigger for a flar coming from the light bridge $\mathrm{A}^{\prime}$ (Figure 15), filling the east glass $\mathrm{I}^{\prime}$ and spreadin along the filament J. Finally there was strong flare activity beginning at $2130 \mathrm{UT}$ In its late stages (Figure 16) the 2215 UT flare extended partially to cover the umbr of the large spot and to completely cover the first and part of the second spots of th triple spot group in the characteristic 2-strand fashion noted by Dodson. Most event on this day were preceded by some sort of activity in the $\mathrm{Z}$ region. There was a radi. storm all day at dekameter and meter wave lengths, but it is sometimes possible, a already noted, to pick out coincidence of flares with various strong bursts supet imposed on this background.

By Sept. 19 the large spot A had split into three parts (Figure 17a) - one of th 


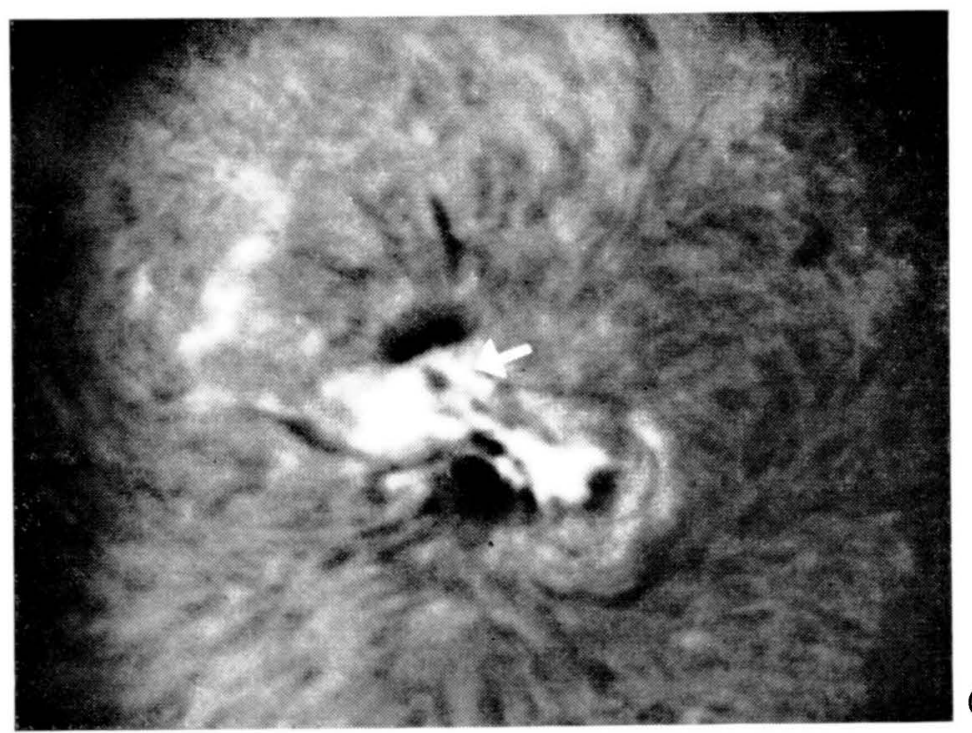

(a)

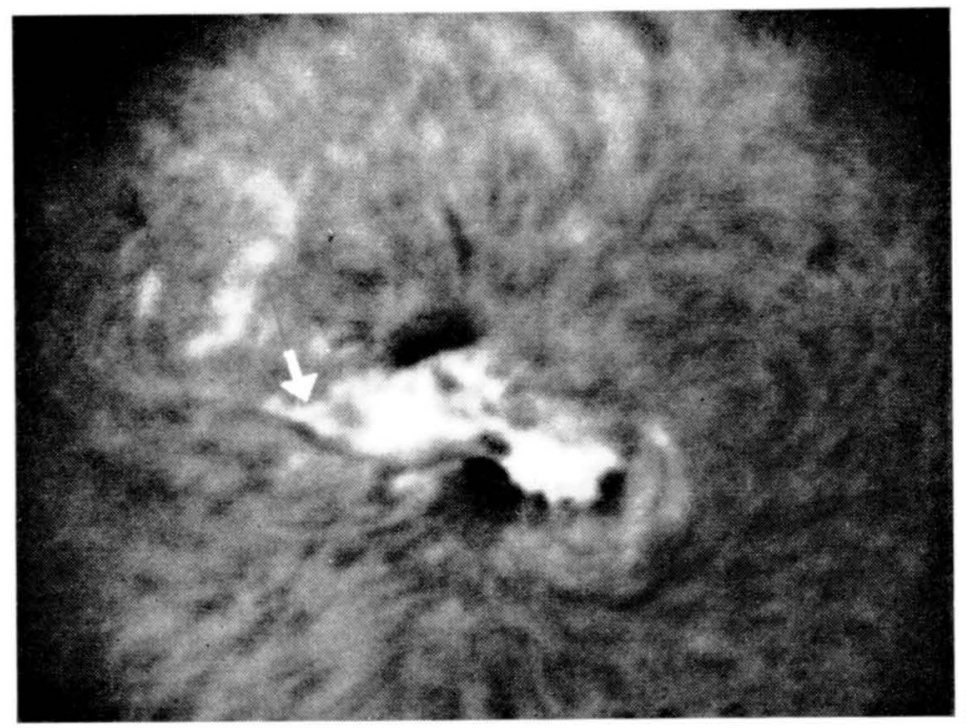

(b)

Fig. 15. Sept. 18. (a) 1700 UT. Flare begins in light bridge $A^{\prime}$, immediately preceded by flash in bright arm $\mathrm{H}^{\prime}$ (arrow). SFD and intense type III burst occurred. - (b) 1703 UT. Flare spreads across bay of flares I and west along filament. $\mathrm{N}$ upper right, $\mathrm{E}$ lower right.

dividing lines was more or less where the flare had crossed the large umbra at 2215 UT on the 18th. Although no flares of importance greater than 1- occurred during our short period of observation, there was continual activity, including many small brightenings and a continual waving about of the large filament $\mathbf{J}$ (Figure 17b). A small dark surge below the triple spots at 1355 UT and a very small flare at $\mathbf{P}$ at 1417 UT next to the large umbra were accompanied by $108 \mathrm{Mc}$ radio bursts. Again much activity occurred near the $\mathrm{Z}$ region of steepest magnetic field gradients but the most intense activity was east of A near the small spots broken off from the main umbra. Minor flare activity was observed in the eastern plage region I. A small new spot appeared at $\mathrm{C}$ with a very small flare at $1350 \mathrm{UT}$. On some of the pictures 
(a)
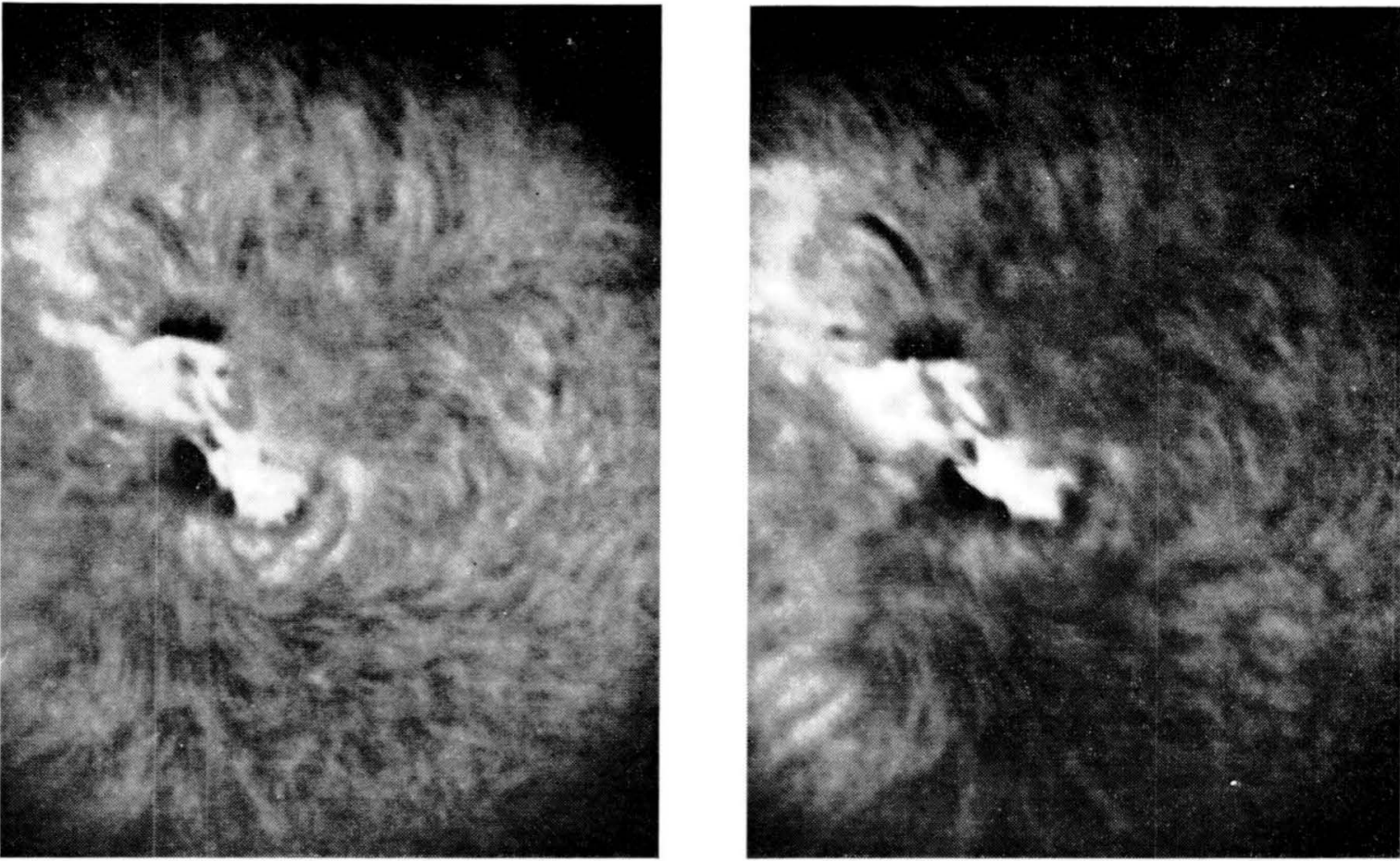

(b)
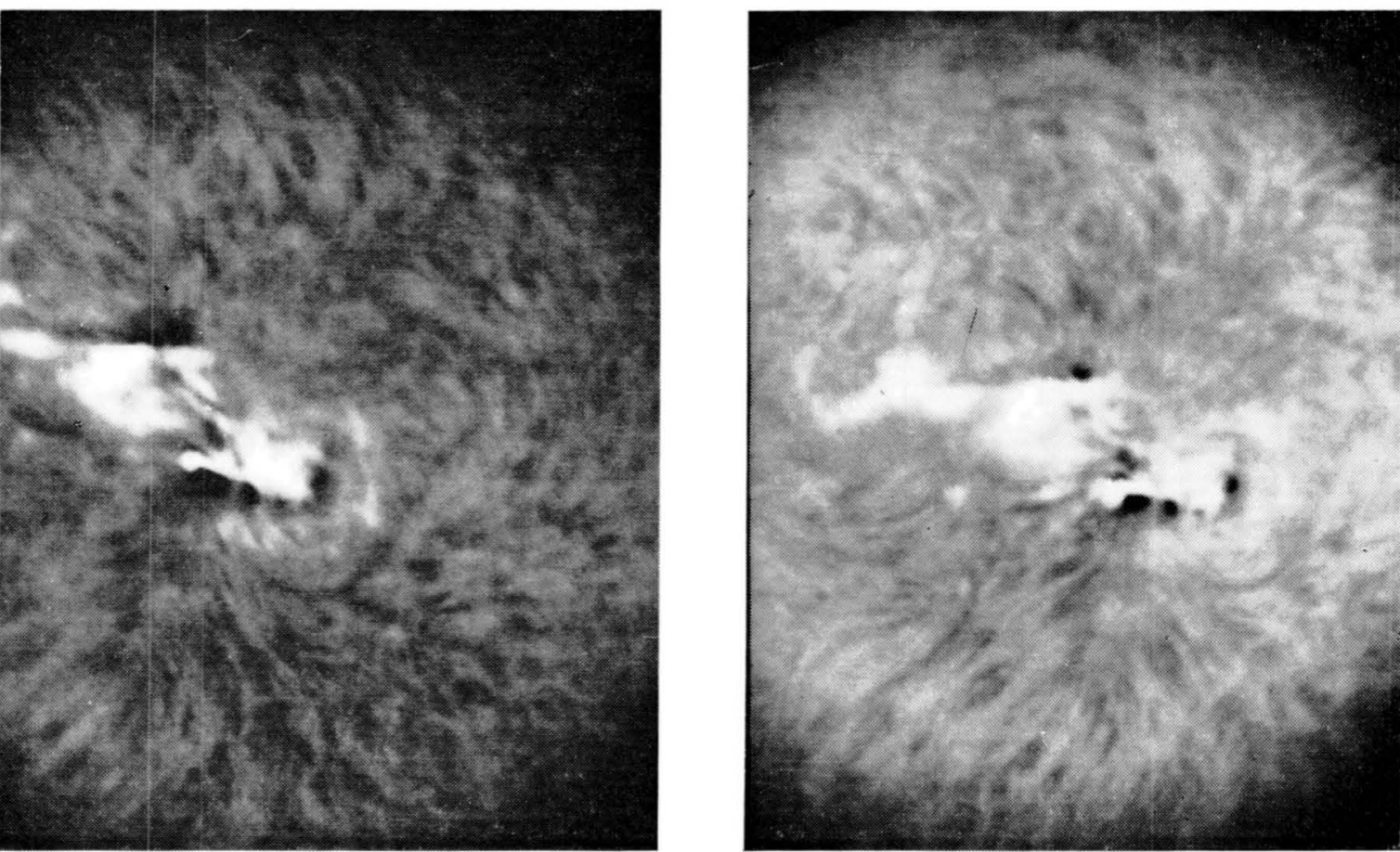

(d)

Fig. 16. Sept. 18. (a) 2146 UT. Flare southeast of triple spots. This activity spreads until (b) major brightening begins in the bay I at $2233 \mathrm{UT}$, and is accompanied by major radio bursts and a spray at D. - (c) 2255 UT. Flare crosses triple spot. - (d) 2339 UT. Late in the flare sequence the appearance is similar to the Sept. 20 flare filmed by Lockheed (Figure 18). W upper left, $\mathrm{N}$ upper right. 


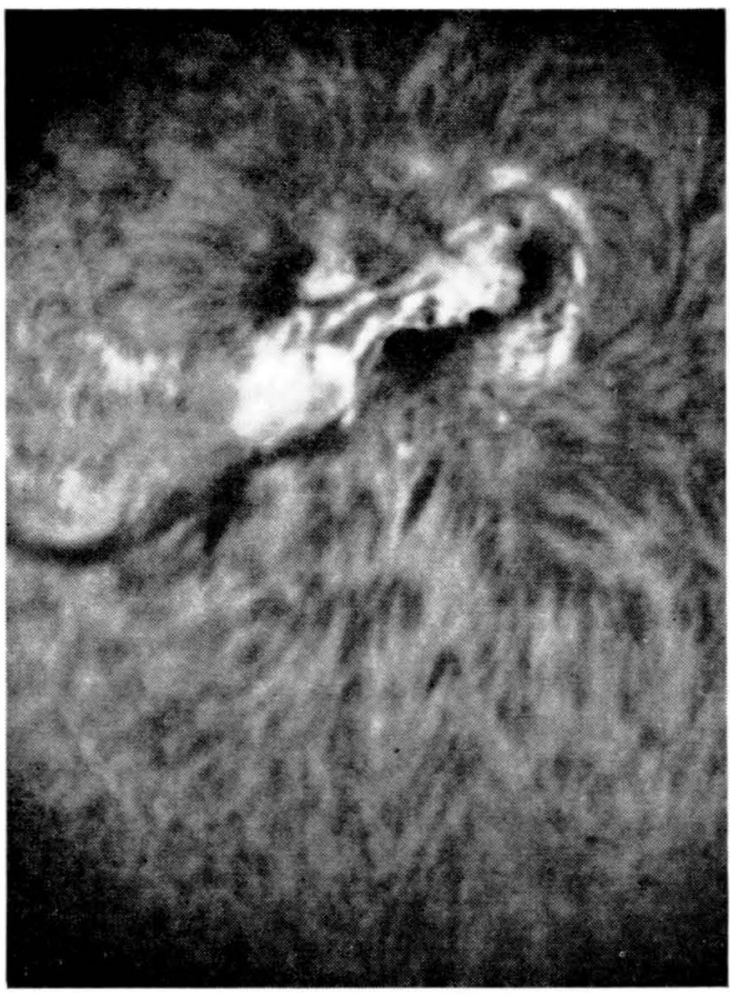

(a)

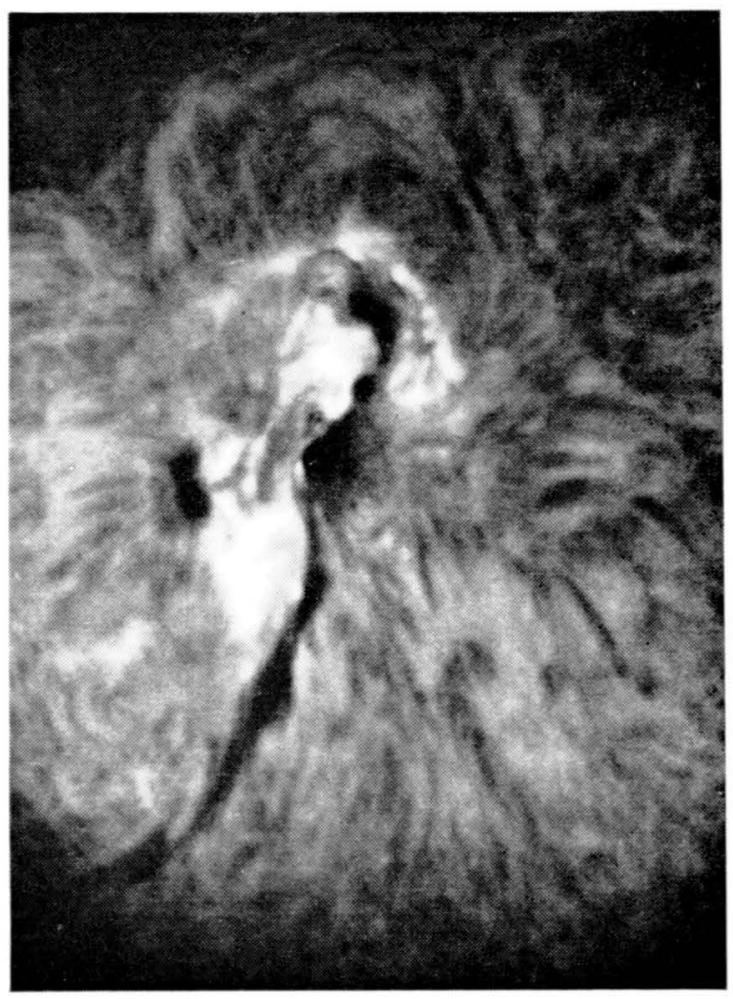

(b)

Fig. 17. Sept. 19. This was a day in which continual motion of the large filament $J$ was observed. Note the difference in structure in the filament at (a) 1419 UT and (b) 1621 UT. The image rotation between the two frames is due to diurnal motion seen from the coudé.

\section{TABLE IV}

19 September 1963. Observation period: 1344.00-1822.00 UT

\begin{tabular}{|c|c|c|}
\hline Location & Time (UT) & Event \\
\hline $\mathbf{J}$ & 1344 & $\begin{array}{l}\text { Continuous motion in long filament, intensifies at } 1407 \text { and lasts to } 1822 \\
\text { (Figure } 17 \mathrm{a}, \mathrm{b} \text {.) }\end{array}$ \\
\hline $\mathrm{C}$ & 1350 & $\begin{array}{l}\text { Series of small brightenings in area which becomes prominent plage } \\
\text { region later. }\end{array}$ \\
\hline $\mathrm{Z}$ & $\begin{array}{c}1355-1411 \\
1415\end{array}$ & $\begin{array}{l}\text { Small dark surge below triple spots south of } Z \text {. } \\
\text { (108 Mc burst.) }\end{array}$ \\
\hline $\mathbf{P}$ & $1412-1429$ & $\begin{array}{l}\text { Small flare }(1-) \text { in neck P. (Figure 17a.) } \\
(3 \text { simple } 3.1517-1647-1717 .) \\
(108 \text { Mc burst, BoN.) }\end{array}$ \\
\hline G, L & $\begin{array}{c}1604 \\
1610-1615\end{array}$ & $\begin{array}{l}\text { Fast flash at G; also along filament } \mathrm{L} \text {. } \\
\text { (Burst BoN, } 108 \mathrm{Mc} \mathrm{Bv} \text { ) }\end{array}$ \\
\hline I & 1630 & Flare $(1-)$, spreads across region, followed by violent wave through \\
\hline $\mathbf{J}$ & 1650 & filament. Widespread but not intense brightening. \\
\hline
\end{tabular}

obtained it is possible to see the lower arms of some of the loops which are formed by the return of the ejected material to the surface of the sun.

Excellent observations were obtained by the Lockheed Solar Observatory of a large flare on Sept. 20 (Figure 18). This "Class 2" flare produced a series of large ionospheric effects, type II and IV radio emission, and a remarkable wave (Figure 18) 
which is seen on the Lockheed pictures to travel across most of the solar surface. We have examined films kindly furnished by Ramsey, for the purpose of comparing the morphology of this important flare with the others that we observed in this period. Although the Lockheed films were made with a smaller image than ours, they are of very high quality, showing considerable detail.

The appearance of the Sept. 20 flare was very similar to that of the class 2 flare at 2303 on Sept. 18. On the 20th the triple spots had moved considerably closer to the main spot, so the general shape of the region was considerably different. Nevertheless the flare started somewhere near the neck $Z$ and spread westward along the filament. An enormous spray was emitted in the flash phase; the Lockheed observations showed that this was overtaken and apparently accelerated by the magnetohydrodynamic surface wave. The ejected material and the wave both traveled outward in a southwesterly direction formerly marked by the filament $\mathbf{J}$ (which later reappeared). This path was followed by surface and excitation waves from almost every large flare in the region, as was apparent from activity in the filament in every case.

(a)
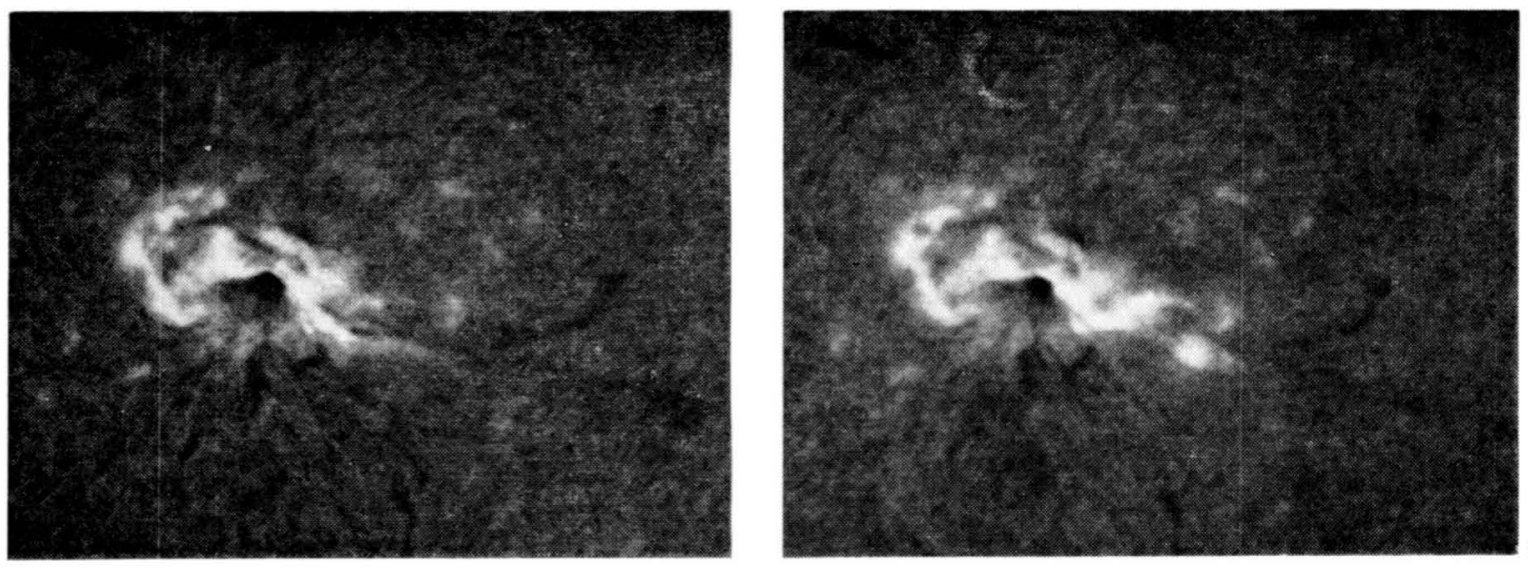

(b)

(c)
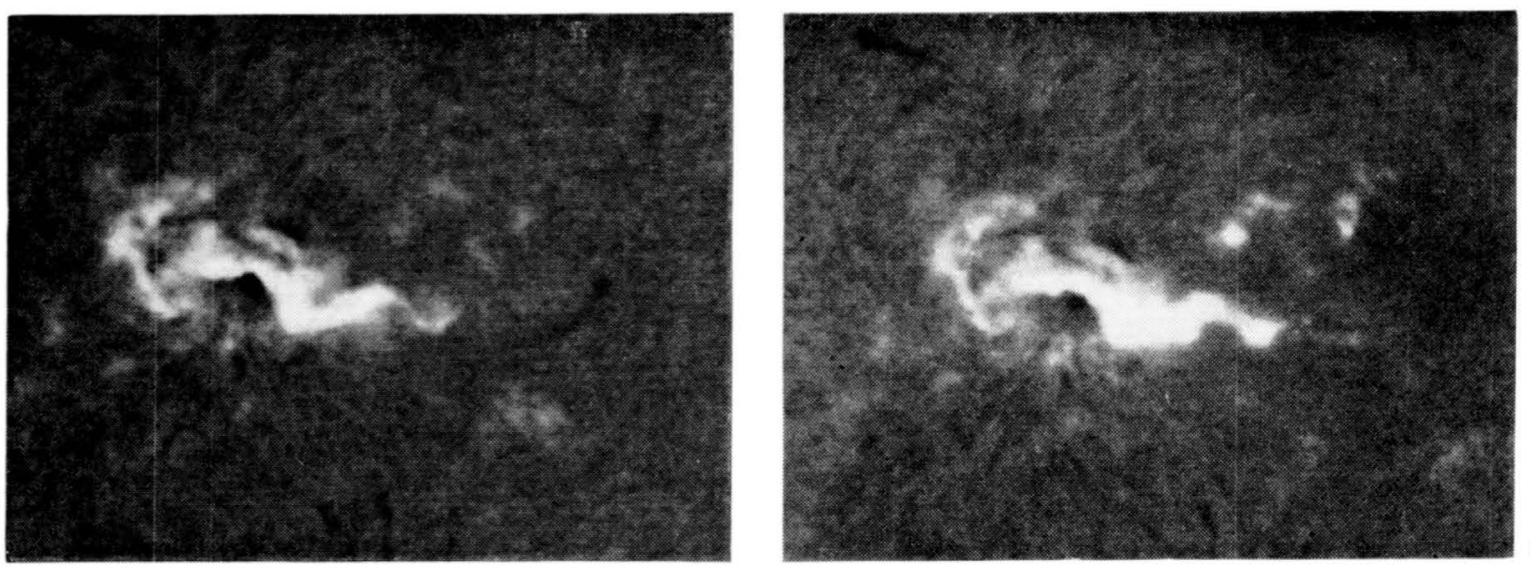

(d)

Fig. 18. Sept. 20. Four stages in the great flare as photographed by Lockheed Solar Observatory. (a) 2349 UT. - (b) 2353:10 UT. - (c) 2357:10 UT. - (d) 2359:40 UT. N top, E right. The flare wave moved off to the west (right). Compare with the flares in Figures 12 and 16. 


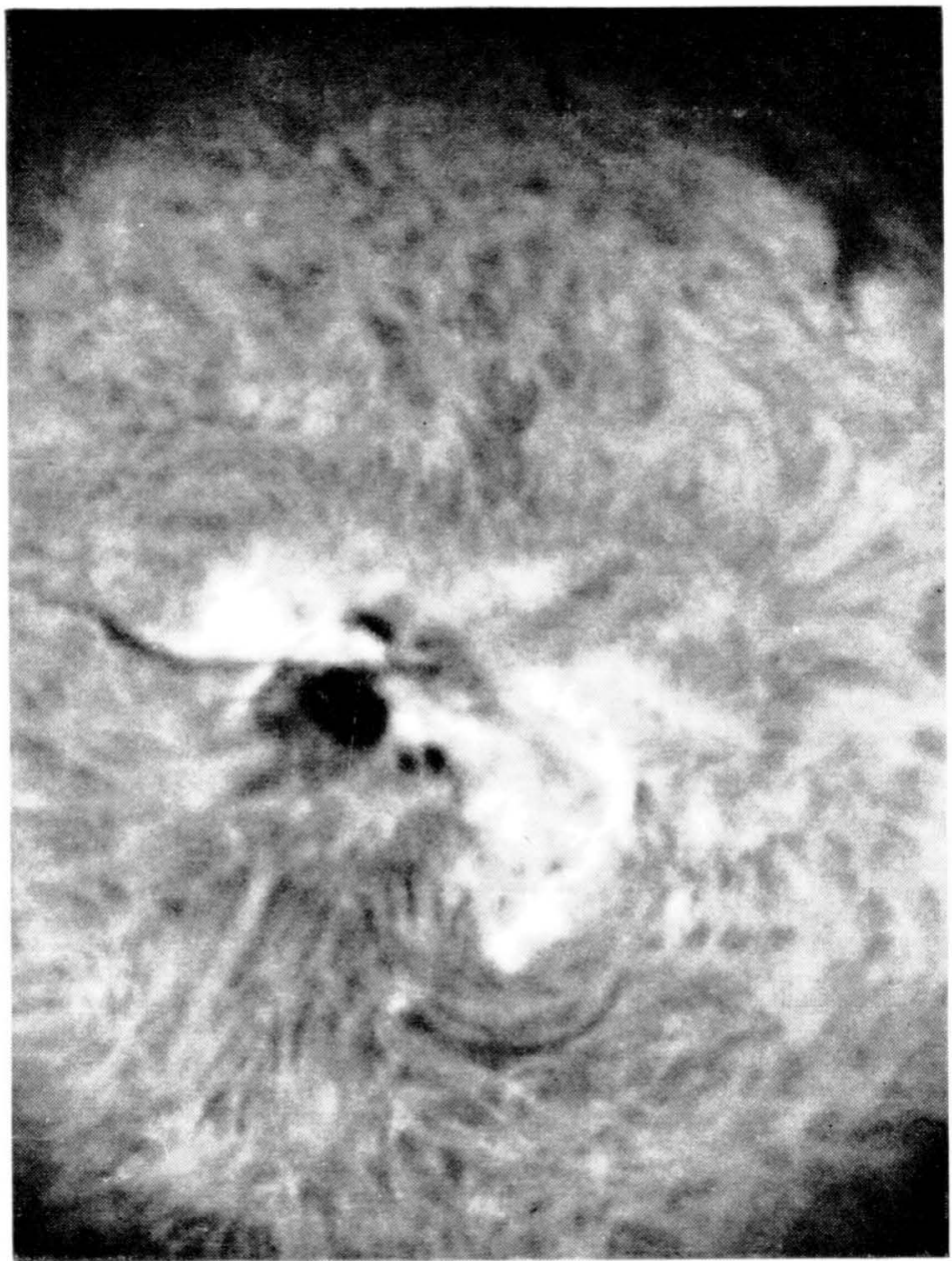

Fig. 19. Sept. 22, 2210 UT. This day was very quiet. The old plage I, along the comma of spots is replaced by a new plage $I^{\prime}$ concave to the $S$. A small flare is in progress at $A^{\prime}, W$ of the large spot.

By September 22 the appearance of the region had considerably changed (Figure 19). The triple spot configuration had disappeared and there remained only a small spot of north polarity opposite the main spot. The plage region had greatly decreased in area although it still showed the overall hourglass shape. The east branch of the hourglass was now dominated by a bright region $\mathrm{I}^{\prime}$ arching northward. All that remained of the long comma (F) of spots were two small spots directly east of the large spot. The neck $Z$ between these still connected the two glasses of the hourglass. Although the magnetic configuration may have changed since the last Mt. Wilson measurements on the 20th, the well-developed filament which cut through the group marked the neutral line separating opposite polarities. The umbra A appeared as a single spot on this day. There were a few flares around $\mathrm{Z}$. In general, however, the region was very quiet on the $22 \mathrm{nd}$; a few small surges and brightenings occurred, all of which are listed.

On September 23 activity increased in the region, although the general magnetic configuration and distribution of plage did not seem to have changed. On this day there was a remarkable flow of disturbance back and forth across the region, with 
TABLE V

22 September 1963. Observation Period: 2103-0035.00 UT

\begin{tabular}{ccl}
\hline Location & Time (UT) & \\
\hline $\mathrm{I}^{\prime}$ & 2113 & Small. \\
$\mathrm{Z}$ & 2120 & Small flare (1-). \\
& 2122 & (Weak type III.) \\
$\mathrm{I}^{\prime}$ & $2152-2158$ & Surge; (type III burst.) Numerous small surges here throughout the day. \\
$\mathrm{Z}$ & 2157 & Tiny flare just S of triple spots. \\
$\mathrm{A}^{\prime}$ & $2210-2222$ & Tiny low-intensity flare; (type III burst (Sydney).) \\
& & Repeat brightening. (Figure 19.) \\
$\mathrm{A}^{\prime}$ & 2213 & (Strong type III observed.) \\
$\mathrm{I}^{\prime}$ & 2219 & Large, active flare; no radio bursts. \\
$\mathrm{A}^{\prime}$ & $2220-2222$ & Tiny flare; no radio burst. \\
$\mathrm{Z}$ & 2314 & Tiny flare; no radio burst. \\
$\mathrm{I}^{\prime}$ & $2318-2339$ & Dark surge; begins with a small explosive phase. \\
$\mathrm{Z}$ & 0015 & Small, fast flare.
\end{tabular}

one flare or surge triggering the next. This phenomenon is very easy to see on the films. The disturbances moved back and forth along the axis of the plage defined by the curving neutral line through $\mathrm{Z}$ and the new curved bright plage $\mathbf{I}^{\prime}$ on the northeast side of I. Some disturbances from $I^{\prime}$ moved across the southeast edge of the large spot Z.

\section{TABLE VI}

23 September 1963. Observation period: 1340.00-0037.00 UT

\begin{tabular}{|c|c|c|}
\hline Location & Time (UT) & Event \\
\hline $\mathrm{I}^{\prime}$ & $1421-1425$ & $\begin{array}{l}\text { Small bright bead flies out of filament } I^{\prime} \text { toward } C \text { where the dark surge } \\
\text { appears. (Figure 20) }\end{array}$ \\
\hline $\mathrm{Z}$ & 1425 & Flare at $Z$ along bead trajectory. (Type III burst.) \\
\hline $\mathrm{C}$ & $1428-1507$ & Dark surge shoots out, falls back \\
\hline $\mathrm{Z}$ & 1439,1453 & Sudden flashes west of the 1425 and 1449 flare regions. \\
\hline $\mathrm{Z}$ & 1449 & Repeat of 1425 flare. \\
\hline $\mathrm{I}^{\prime}$ & $1452-1458$ & Plage I' brightens. \\
\hline $\mathrm{Z}$ & 1504 & Repeat of 1425 . \\
\hline $\mathrm{I}^{\prime}$ & $\begin{array}{l}1514 \\
1534\end{array}$ & $\begin{array}{l}\text { Brightening with return of bead (1-). } \\
\text { (Type III burst.) }\end{array}$ \\
\hline $\mathbf{I}^{\prime}, \mathbf{L}$ & 1540 & Large brightening of entire east end of plage. \\
\hline $\mathbf{J}$ & 1638 & $\begin{array}{l}\text { Tiny bright spot along north side of filament } J \text {. } \\
\text { Brightening of plage. }\end{array}$ \\
\hline & 1639 & (Type III.) \\
\hline $\mathrm{Z}$ & 1641 & Dark surge slightly northeast of $\mathrm{Z}$. \\
\hline I & $1652-1739$ & Small surge. \\
\hline $\mathrm{Z}$ & 1713 & Small fast brightening east of $\mathrm{Z}$. \\
\hline $\mathrm{L}$ & $\begin{array}{l}1742,1810 \\
1939\end{array}$ & $\begin{array}{l}\text { Homologous brightening of entire east end of plage, similar to } 1540 \text {. } \\
\text { (Weak type III.) }\end{array}$ \\
\hline $\mathrm{I}^{\prime}$ & 1950 & Large rapid dark surge northeast of I'. \\
\hline $\mathrm{I}^{\prime}$ & 2254 & $\begin{array}{l}\text { Flash. } \\
\text { (Type III's at 2258, 2300, 2305, 2310, 2313, } 2333 \text { UT.) }\end{array}$ \\
\hline $\begin{array}{l}\mathrm{J}, \mathrm{I}^{\prime} \\
\mathbf{I}^{\prime}\end{array}$ & $\begin{array}{l}2314 \\
0027\end{array}$ & $\begin{array}{l}\text { Bright fast flash north of filament. Simultaneous flash in } \mathbf{I}^{\prime} \text {. } \\
\text { Flash. }\end{array}$ \\
\hline
\end{tabular}


(a)
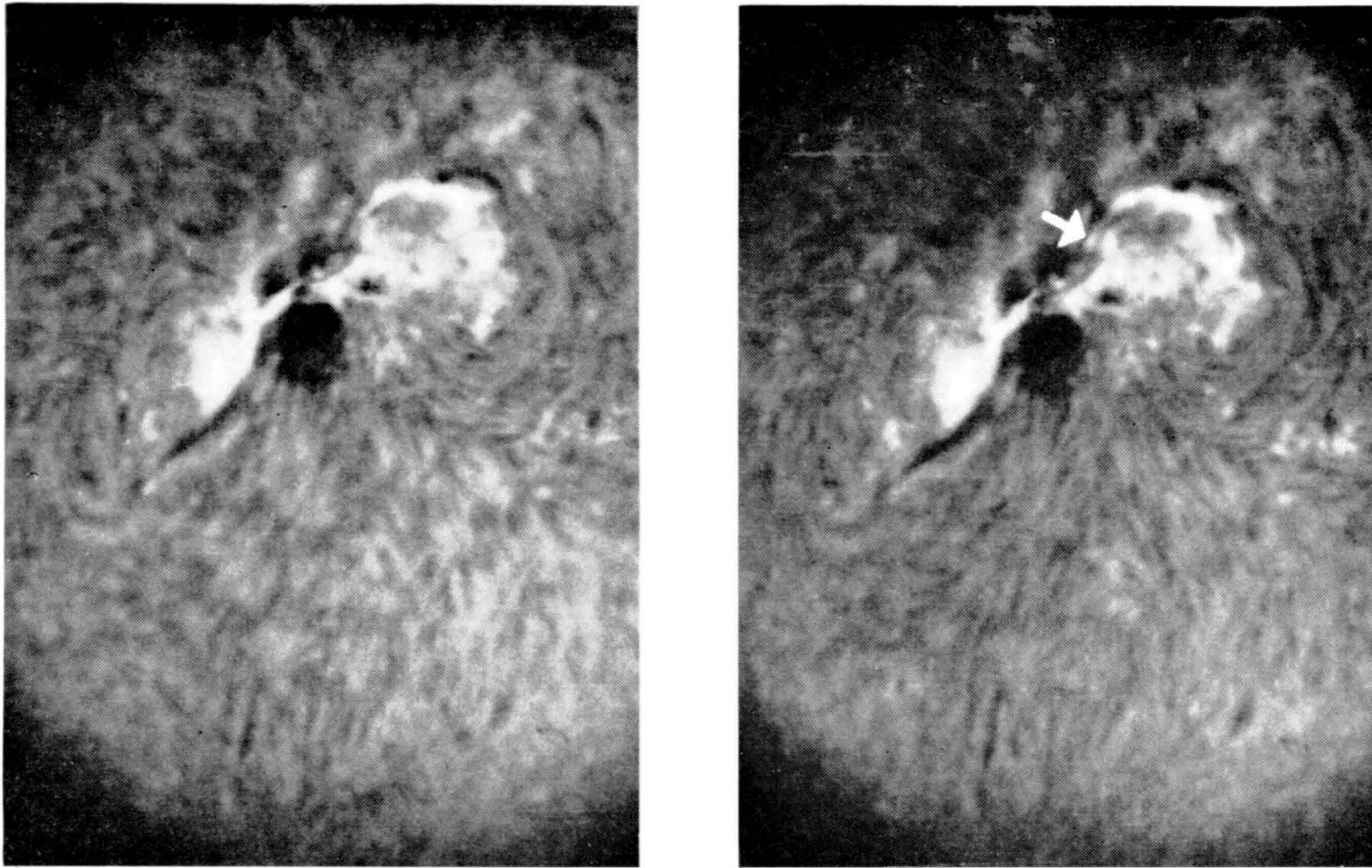

(b)
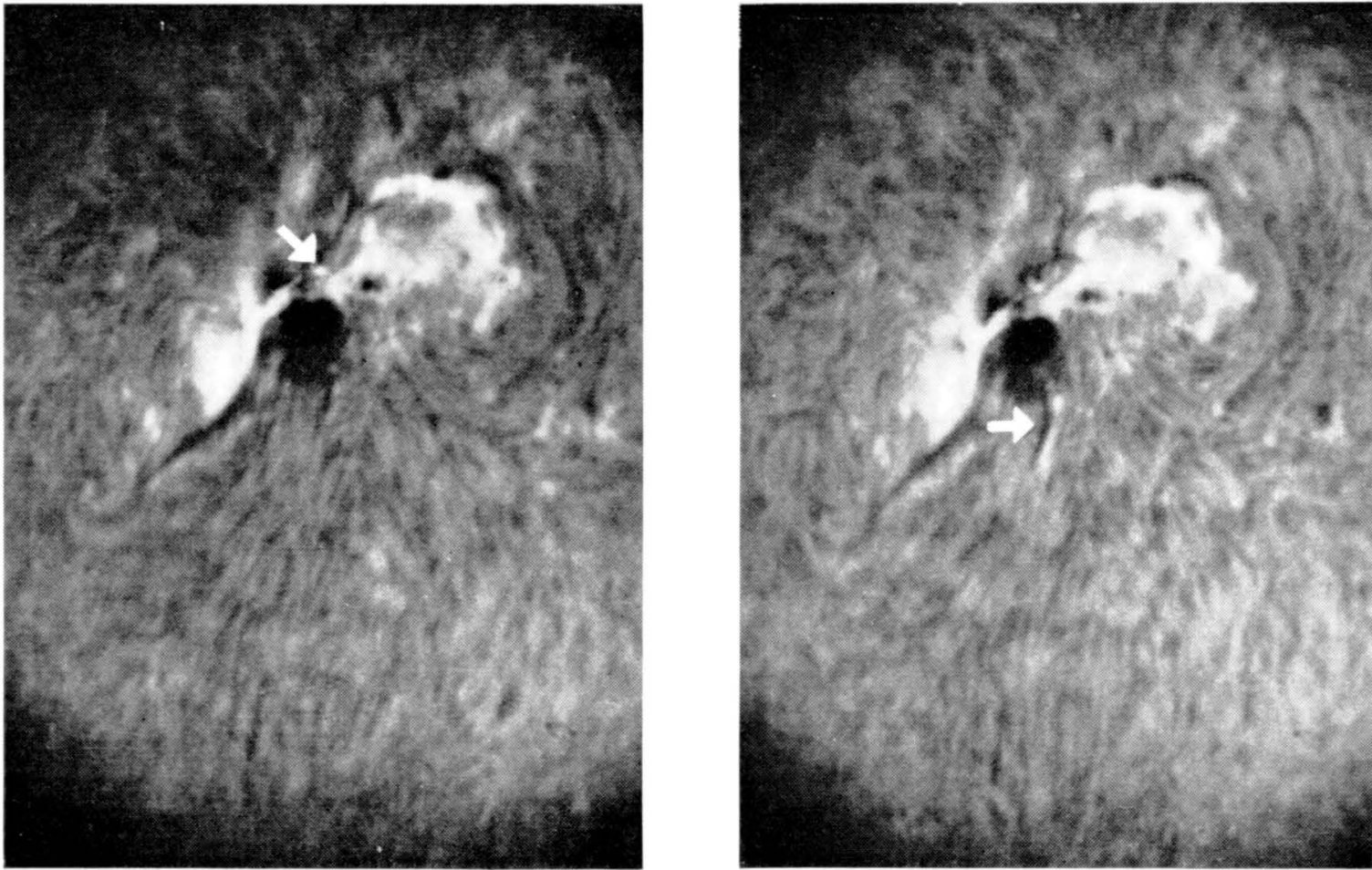

(d)

Fig. 20. Sept. 23. (a) 1422 UT. Plage I' lengthens and (b) at 1434 UT appears to eject a bead which travels (c) along neutral line (1424 UT), producing (d) small flare (1425 UT) and moves on across the spot A to produce a surge (e) from $\mathrm{C}$. After the surge fell back, a return wave produced a second flare in $I^{\prime}$. N upper left, E upper right. 
The most interesting even on our films that day was the appearance of a bright bead (1421-1425 UT) ejected from I' in a SW trajectory across the spot (Figure 20). The bead produced two rapid flares in $\mathrm{Z}$ (in the plage referred to on the 24th, Figure 21 ), and when it crossed the sunspot, also produced a flare and surge at $C$. When the

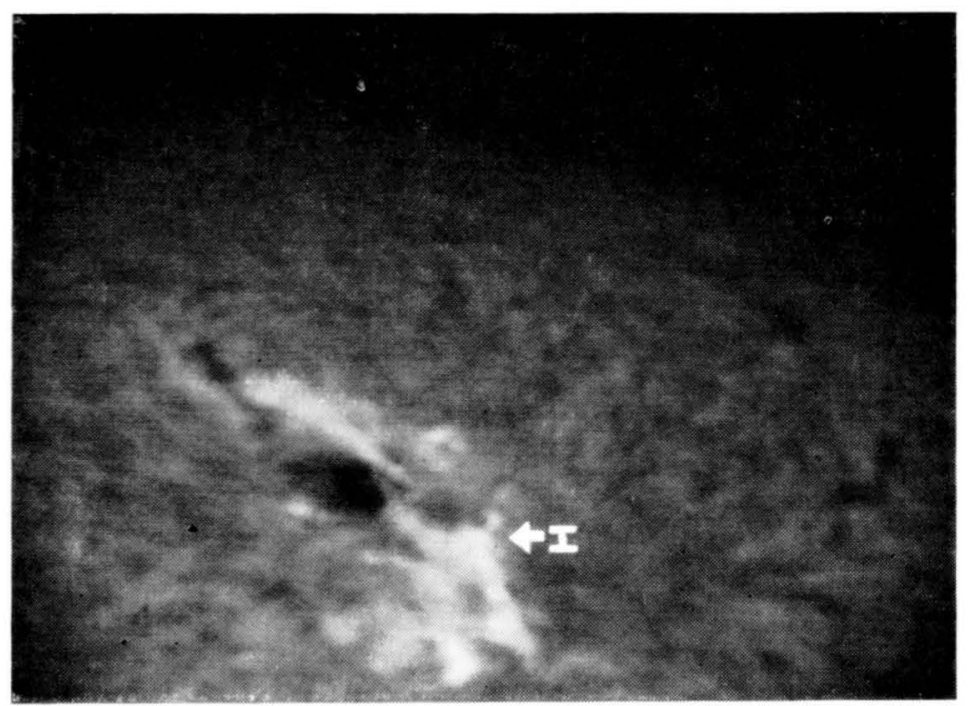

(a)

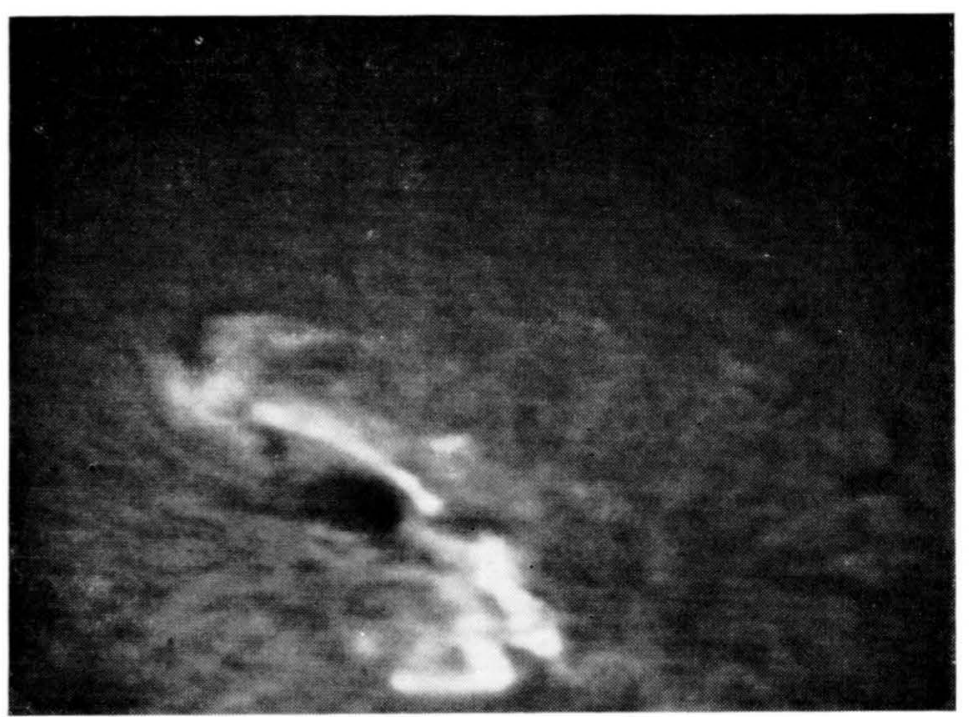

(b)

Fig. 21. Sept. 24, 1439 UT. (a) A bright spray at $I^{\prime}$ initiates a flare which spreads over the entire region, brightening rapidly in one minute at 1446 UT. - (b) The long bright strand northwest of the large spot is probably suspended above it and appears in other flares. $\mathbf{N}$ upper left, $\mathrm{E}$ upper right.

surge returned, a disturbance passed back along this trajectory, the bead reappeared, and the entire $\mathrm{I}^{\prime}$ region brightened, weakly at first, then strongly at 1540 UT. The 1540 UT brightening of the entire plage $\mathrm{I}^{\prime}$ was repeated at 1742 and 1810 UT.

Disturbances traveled back and forth along the main axis of the group (i.e., the line from $I^{\prime}$ through neck $\mathrm{Z}$ and out along the filament) all day.

The activity in the region increased further on the 24 th, as it approached the limb. 
Two very similar explosive flares occurred at the beginning and end of the day. At 1437 UT (Figure 21a) a bright spray was ejected vertically from $I^{\prime}$, accompanied by a strong type III burst. The flash phase occurred at 1442 UT with a rapid spread of brightness across the center of the region and westward along the large filament (Figure 21b). It is interesting that the ionospheric effects coincided with the flash phase at 1446 UT and not the spray ejection-explosive phase at 1438 UT - the same is true of the $2800 \mathrm{Mc} / \mathrm{sec}$ burst. Possibly the flare produced a great increase in the temperature and density of the corona, including enough energetic electrons to

TABLE VII

24 September 1963. Observation period: 1340.30-0033.00 UT

\begin{tabular}{|c|c|c|}
\hline Location & Time (UT) & Event \\
\hline $\mathrm{C}$ & 1417 & Small fast surge-flare. \\
\hline \multirow[t]{2}{*}{$\mathrm{C}$} & 1437 & $\begin{array}{l}\text { Homologous surge-flare simultaneous with major flare brightening (1). } \\
\text { Begins at } I^{\prime} \text { with bright spray. }\end{array}$ \\
\hline & 1438 & (Strong type III. 3 simple 3 ( $\max$ at 1447$)$.) \\
\hline J, I' & 1445 & $\begin{array}{l}\text { Brightening and disturbances spread through entire plage, both } I^{\prime} \text { and } \\
\text { along filament J. Figure } 21 \text {. Continuous violent disturbances moving } \\
\text { out along the filament. ( } 2800 \text { Mc burst; max at } 1447 \text { UT.) This was } \\
\text { probably a class } 2 \text { flare, considering the ionospheric effects. (1445-53- } \\
1515 \text { SPA (1), SLSWF, SEA (2), SES.) }\end{array}$ \\
\hline $\mathrm{D}$ & 1518 & Brightening (1) followed by dark surge. \\
\hline $\mathbf{D}$ & $1539-1559$ & Dark surge followed by brightening at 1549 UT. (Type III.) \\
\hline $\mathrm{D}$ & 1703 & Small brightening (1-) in $\mathbf{D}$; (type III burst.) \\
\hline $\mathrm{L}$ & $1705-1713$ & $\begin{array}{l}\text { Brightening (1-); possibly triggered by small flare at D, with disturbance } \\
\text { moving south, at } 1703 \text { UT. (Two type II's at } 1705 \text { UT and type III at } \\
1726 \text { UT.) }\end{array}$ \\
\hline \multirow[t]{2}{*}{ I } & 1842 & $\begin{array}{l}\text { Disturbance at I. Bright bead similar to that on Sept. } 23 \text { flies out to the } \\
\text { west, while a small dark surge goes east. (Type III burst.) }\end{array}$ \\
\hline & 1919 & (Type III burst.) \\
\hline $\mathbf{L}$ & $\begin{array}{c}1925-1931 \\
1943\end{array}$ & $\begin{array}{l}\text { Bright flash (1-). ( } 2800 \mathrm{Mc}, 1 \text { simple } 1 \text {; no } 30 \mathrm{Mc} \text { burst.) } \\
\text { (Weak type III) }\end{array}$ \\
\hline $\mathrm{Z}$ & 1944 & Flares (1-). \\
\hline $\mathbf{L}$ & 1957 & Spray of low brightness. \\
\hline \multirow[t]{2}{*}{$\mathbf{L}$} & $2024-2055$ & $\begin{array}{l}\text { Spray (1-) in progress. New spray begins at } 2029 \text { UT. Comes back down } \\
\text { rather violently at } 2034 \text { UT. }\end{array}$ \\
\hline & 2103 & (Medium type III.) \\
\hline \multirow[t]{2}{*}{$\mathbf{D}$} & $2113-2121$ & Bright high surge. \\
\hline & 2114 & (Very weak type III.) \\
\hline \multirow[t]{3}{*}{$\mathrm{C}$} & 2118 & Fast umbral flash at C (in 3 frames). (Type III.) (Figure 22) \\
\hline & $2125-2135$ & Fast brightening. \\
\hline & 2149 & Flare near umbra. \\
\hline $\mathbf{I}^{\prime}$ & 2155 & Fast brightening with dark surge. \\
\hline \multirow[t]{5}{*}{$\mathbf{I}^{\prime}$} & $2204-2225$ & Dark surge. \\
\hline & 2202 & (Type III.) \\
\hline & 2204 & (Type III.) \\
\hline & 2219 & (Strong short type III;) dark filament gradually appears. \\
\hline & 2337 & (Type III.) \\
\hline $\mathbf{L}$ & 2337 & Small "trigger" brightening at $\mathbf{L}$. \\
\hline \multirow[t]{2}{*}{$\mathrm{I}^{\prime}, \mathrm{L}, \mathrm{Z}$} & 2343 & $\begin{array}{l}\text { The entire region explodes (1-?). (Weak III's at } 2349 \text { and } 2353 \text { UT.) } \\
\text { (Figure 23.) }\end{array}$ \\
\hline & 2345 & (Strong type III.) \\
\hline
\end{tabular}


produce the non-thermal radiation which accounts for the ionospheric effects. During the flare there was a pronounced waving and changing of the filament at the west, and successive surface MHD waves traveled out along this neutral line, in the general direction followed by the large Sept. 20 wave.

This flare was observed by six stations and classed as importance 1 by all; it probably should rank as importance 2 . The reason for this discrepancy is no doubt its proximity to the limb.

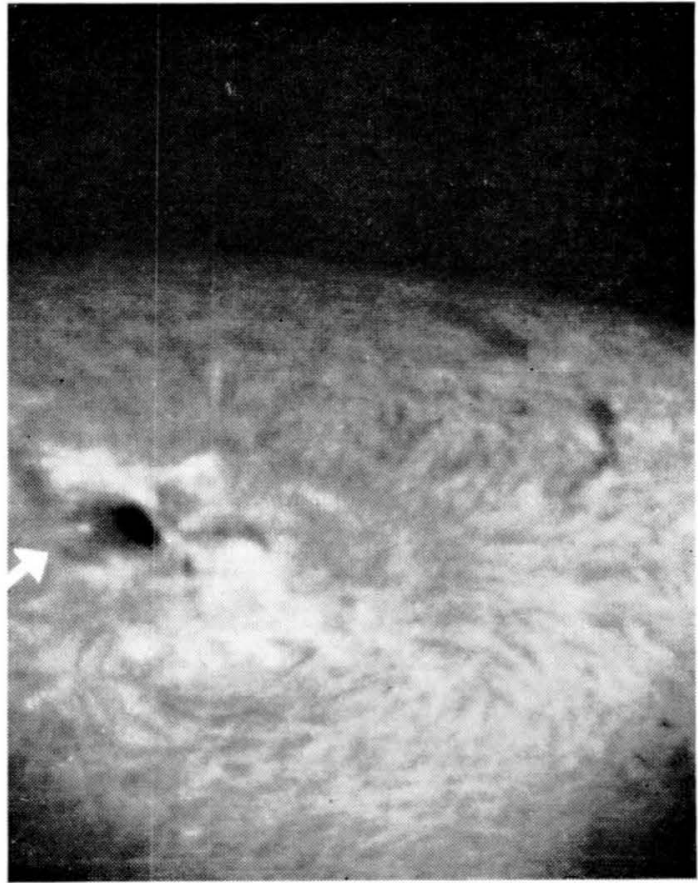

(a)

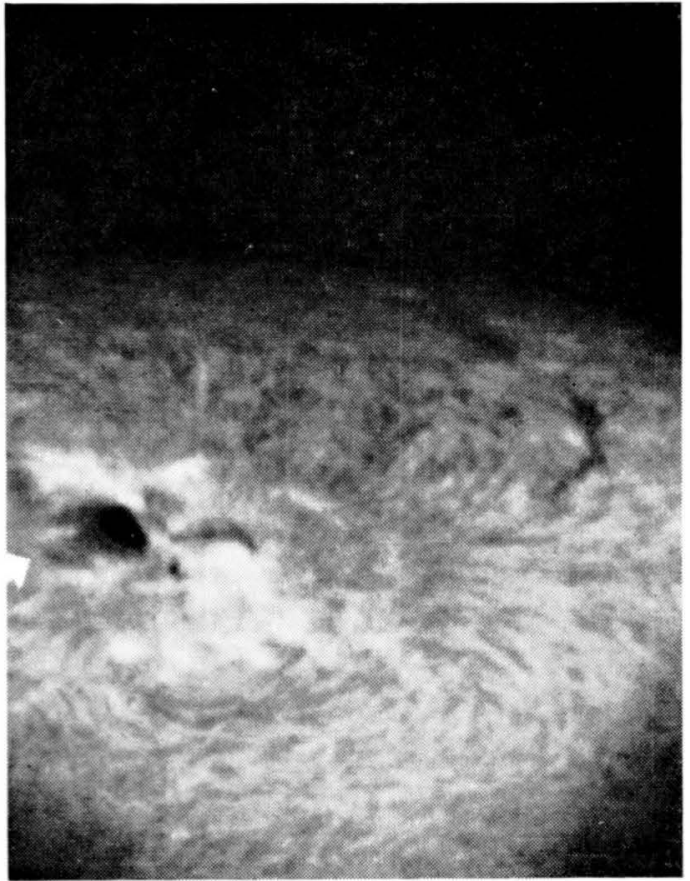

(b)

Fig. 22. Sept. 24, 2118 UT. Umbral flash (arrow) shoots out of penumbra to the left. (a) 2118:15 UT. - (b) 2118:30 UT. This flare only appeared on 3 frames but produced a moderate type III burst. $\mathrm{N}$ upper right, $\mathrm{W}$ upper left.

Figure $22(\mathrm{a}, \mathrm{b})$ captures a very rapid umbral flash. Within 12 seconds the small area at $\mathrm{C}^{\prime}$ brightened and material appeared to squirt out very rapidly to the southwest. We have observed about six such flares in other large sunspots. They always are short-lived, relatively faint, and limited to a sector of $20^{\circ}$ or less. All the ones that we have seen produced type III bursts. They may appear in the penumbra of a round spot, or come out of a light bridge or notch in the spot. In round spots a faint plage may be seen leading up to the umbra in the flare sector.

During the rest of the observing period on the 24th there were numerous small brightenings, some of which were accompanied by radio bursts, but the general noise storm limited the number of clear events. At 2343 UT (Figure 23) there was a very rapid explosive flare at $\mathrm{I}^{\prime}$, possibly triggered by a nearby brightening at 2338 UT. In a few minutes the entire region erupted in a bright spray, with simultaneous brightening of different distant points. 

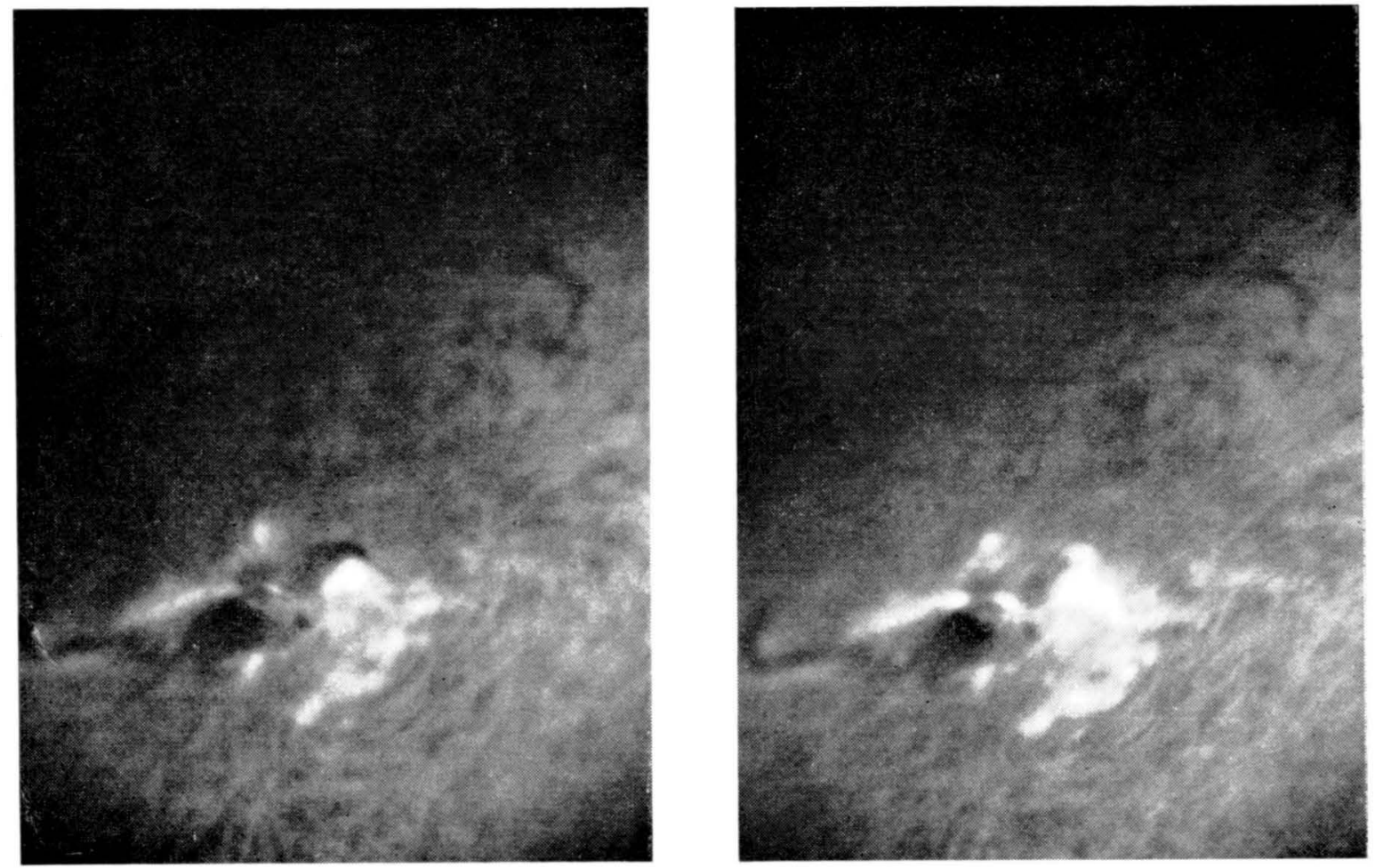

(a)

Fig. 23. Sept. 24. Explosive flare. (a) At 2342 UT a faint flash repeated at the point of the 2118 UT umbral flash. At 2344 UT the neck Z brightened for a minute and faded. (The large looped filament appeared around 2300 UT.) Then at 2345 UT. - (b) the flare exploded outward from I', spreading across the entire region. This flare deserved more than its official 1 - designation. $\mathrm{N}$ top, $\mathrm{E}$ right.

The 25th of September was one of the most interesting days of this period. The region was one day from the limb, and the height resolution obtained gives a nice three-dimensional effect to the pictures. In addition the seeing remained good all day. The radio noise storm was limb-darkened by the 25 th, so that single radio bursts were easy to pick out. New activity appeared to the south of the main spot in $\mathrm{C}$ in an area previously fairly quiet except for small surges. All day long there were small bright flares in $\mathrm{C}$ and the surrounding area. One type is shown in Figure 24; it repeated several times during the day. The sharp rise in brightness occurred in less than one minute at 1415 UT, accompanied by strong type III bursts at 1415 and 1417 UT. Surge flares, bright and dark, occurred at $\mathbf{C}^{\prime}$ numerous times. An example is shown in Figure 25. Another type of flare in part of this region occurred at $1842 \mathrm{UT}$ (Figure 26) and 2134 UT. Although these flares were smaller in area, they produced intense type III bursts - the first was also observed in the centimeter range at Ottawa. All of the flares referred to were in situ flares, represented by rapid brightening with no apparent motion. A very interesting aspect of these flares is that every one in and around region $\mathrm{C}$ produced a strong type III burst on the rather sensitive Boulder records. There were a few flares outside this area during the day - none of them produced radio emission. Apparently the conditions in this region were auspicious for repeated flares and for the production of the energetic streams or waves that 

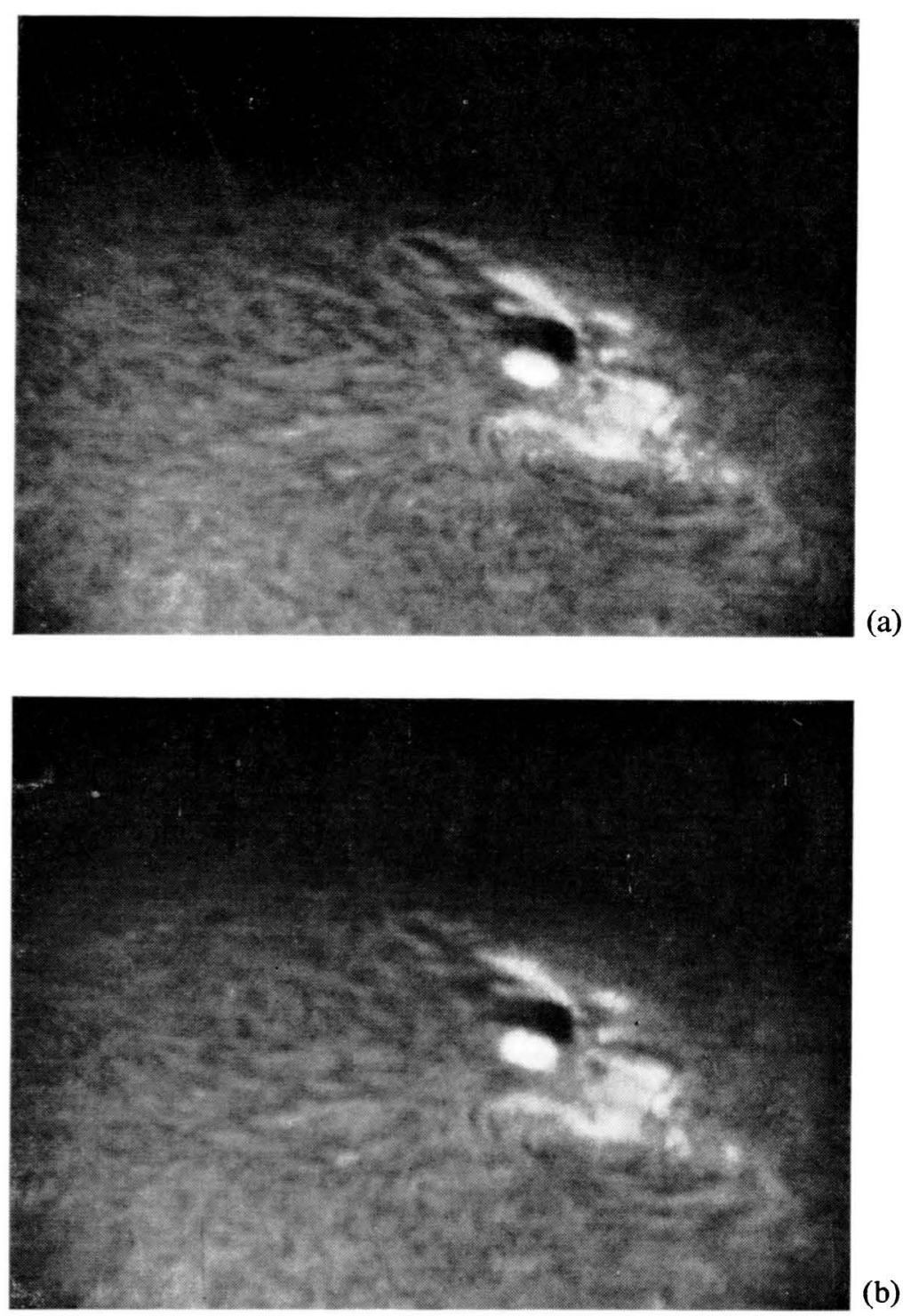

Fig. 24. Sept. 25. This flare is typical of several in situ flares at $C$ on this day. (a) Region at 1413 UT. - (b) 1415:30 UT with sharp rise to maximum brightness at (c) 1416 UT. W top, N right.

produce type III bursts. There even seems to be a general similarity (not surprising) between bursts from homologous flares, but there is insufficient structure to make definite conclusions on this score.

Late in the day there was another large explosive flare from region $\mathrm{I}^{\prime}$, very similar to the two of the 24th, but with differences that the reader may judge from the illustrations (Figure 27). It is interesting that this flare was closely preceded (triggered?) by a surge flare in $\mathrm{C}$, and also followed by one; both these flares produced much larger radio bursts than the explosive flare. It is possible to watch the wave of excitation move across the group and trigger the last flare.

In each of the flares a dark prominence (at $I^{\prime}$; $E$ of the spot, in Figures 22, 23, and 24) builds up before the flare, similar to the effect noted by the Lockheed ob- 


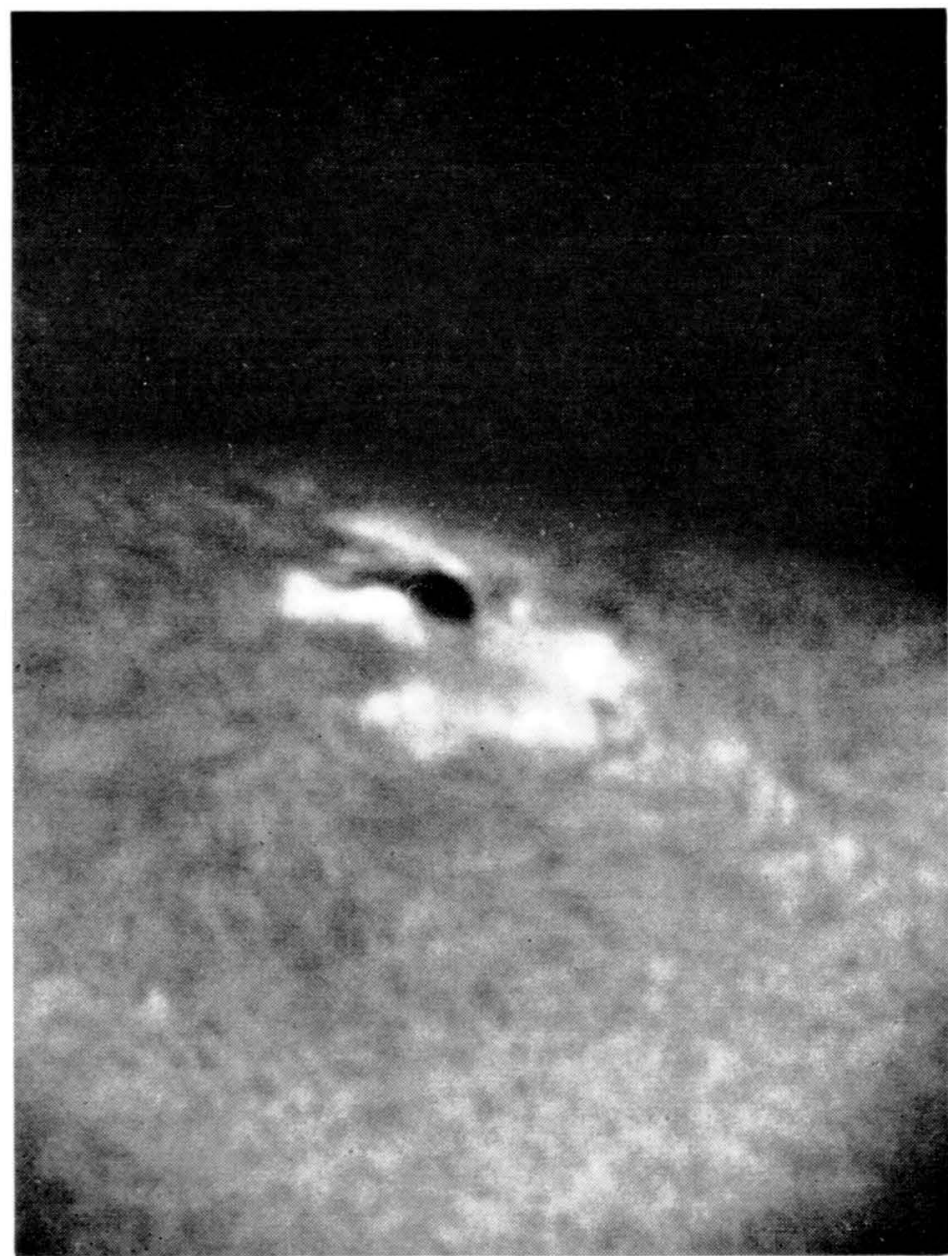

Fig. 25. Sept. 25. Bright surge flare 1823 UT. Several of these occurred at $C^{\prime}$ on this day, accompanied by similar type III bursts. $\mathrm{W}$ top, $\mathrm{N}$ right.

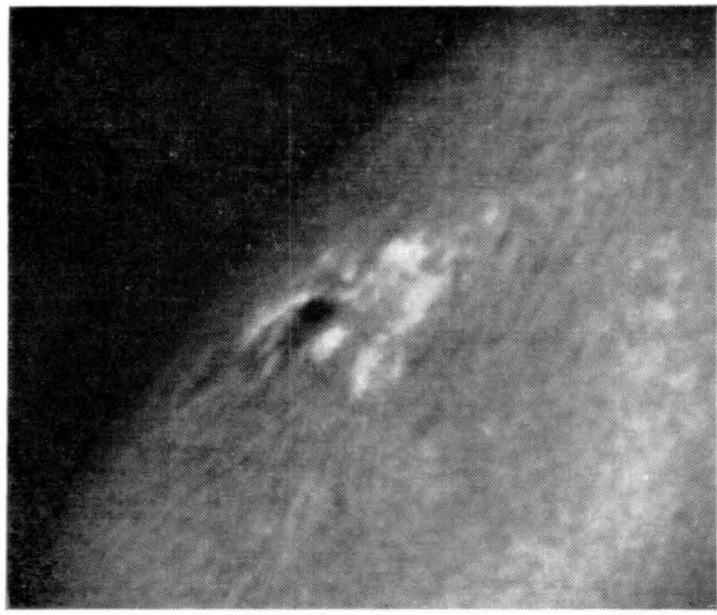

(a)

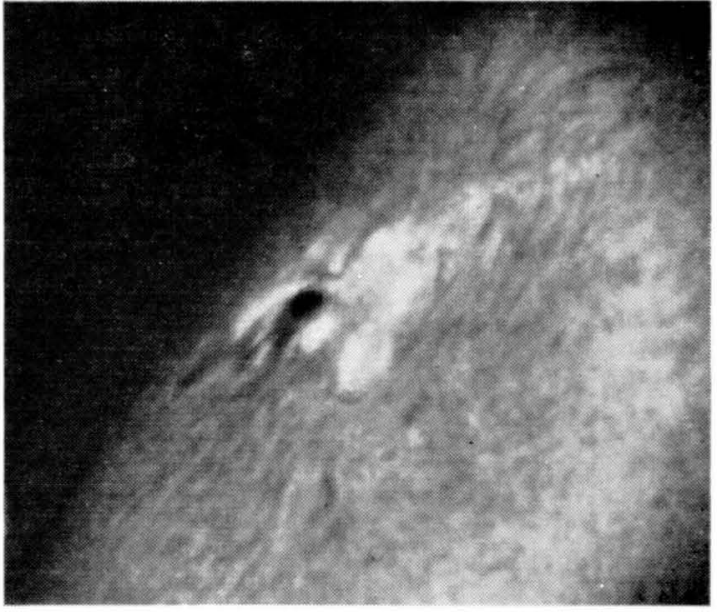

(b)

Fig. 26. Sept. 25. Small (1-) in situ flare at C. (a) 1842 UT. - (b) 1846 UT. This flare produced an intense type III burst despite its small size. 
TABLE VIII

25 September 1963. Observation period: 1339.4-0033.00 UT

\begin{tabular}{|c|c|c|}
\hline Location & Time (UT) & Event \\
\hline $\mathrm{C}$ & 1347 & Small brightening south of spot A; (type III bursts.) \\
\hline $\mathrm{C}$ & $1358-1402$ & Flare (1-) south of spot A. Maximum at 1400 UT. \\
\hline $\mathrm{C}$ & $1412-1425$ & $\begin{array}{l}\text { Bigger flare, same place, with dark surge from center. Maximum at } 1417 \\
\text { UT. Blows off bright material at maximum brightness, turning to dark } \\
\text { surge at } 1423 \text { UT. (Figure } 24 \text {.) }\end{array}$ \\
\hline & 1415,1417 & (Very intense long type III bursts.) \\
\hline & 1429 & (Medium type III.) \\
\hline $\mathrm{C}$ & 1451 & Large dark surge. (Type III at 1448 UT.) \\
\hline C & $\begin{array}{c}1455 \\
1520,1559\end{array}$ & $\begin{array}{l}\text { Small brightenings on north edge of area } \mathrm{C} \text { with long surge. } \\
\text { (Intense type III.) }\end{array}$ \\
\hline $\mathrm{C}$ & $\begin{array}{l}1609 \\
1611\end{array}$ & $\begin{array}{l}\text { Small brightening with surge. } \\
\text { (Weak type III.) }\end{array}$ \\
\hline $\mathrm{Z}$ & 1614 & Brightening (1-) with ejection of matter. Repeated at 1623 . \\
\hline $\mathrm{C}$ & 1633 & Flash (immediately preceded by smaller one.) \\
\hline $\mathbf{Z}$ & 1633 & Small brightening. General brightening of $\mathbf{I}^{\prime}$. \\
\hline C & $\begin{array}{l}1641 \\
1643\end{array}$ & $\begin{array}{l}\text { Brightening. } \\
\text { (Intense type III.) }\end{array}$ \\
\hline$A^{\prime}$ & 1658 & Rapid flash. \\
\hline $\mathrm{Z}$ & $1717-1725$ & Small flash. \\
\hline C & $1729-1735$ & Small flash. \\
\hline $\mathbf{L}, \mathbf{I}^{\prime}$ & $1730-1739$ & $\begin{array}{l}\text { Flare (1-) simultaneous with brightening of two points of } \mathrm{C} \text { (identical } \\
\text { with } 1842 \text { UT.) }\end{array}$ \\
\hline A & $1757-1774$ & Spray from A to the southwest more or less along $\mathrm{C}$. \\
\hline $\mathbf{C}^{\prime}$ & 1823 & Surge flare. \\
\hline $\mathbf{C}$ & $1842-1850$ & $\begin{array}{l}\text { Small flare (1-). Max. at } 1843 \text { UT. (Very strong III (Boulder), } 2800 \mathrm{MC} \\
\text { burst (Ottawa) group of III's observed at Ft. Davis.) The two points of } \\
\text { C that brighten here show many small brightenings during the day. } \\
\text { Figure } 26 .\end{array}$ \\
\hline $\mathbf{C}^{\prime}$ & $1958-2023$ & Bright surge. \\
\hline $\mathbf{C}^{\prime}$ & $\begin{array}{l}2000-2011 \\
2025\end{array}$ & $\begin{array}{l}\text { Small dark surge. } \\
\text { (Medium type III.) }\end{array}$ \\
\hline $\mathbf{C}^{\prime}$ & 2029-2043 & $\begin{array}{l}\text { Small flare (1-); triggers the following event. } \\
\text { (Group of type III's.) }\end{array}$ \\
\hline $\mathrm{C}$ & 2037-2049 & $\begin{array}{l}\text { Bright flare homologous with } 1958 \text { UT (1-) with large ejection of matter; } \\
\text { max. at } 2039 \text { UT. } \\
\text { (Intense type III's.) }\end{array}$ \\
\hline A & $2134-2142$ & Small brightening all through the area near umbra $\mathrm{A}$. \\
\hline C & $2201-2225$ & $\begin{array}{l}\text { Small brightening with major ejection of matter along } \mathrm{C}^{\prime} \text { (bright surge); } \\
\text { (medium type III burst.) }\end{array}$ \\
\hline $\mathrm{C}^{\prime}$ & 2251 & Bright surge north of $\mathrm{C}^{\prime}$; (strong type III at 2308 UT. (1-).) \\
\hline & $\begin{array}{l}2313 \\
2317\end{array}$ & $\begin{array}{l}\text { (Group of weak type III's.) } \\
\text { General brightening. (Figure } 27 \text {.) Propagates along extended lower plage } \\
\text { region and out into region } 2 \text {. }\end{array}$ \\
\hline $\mathrm{C}$ & $2330-2336$ & Large spray; (group of weak type III's.) \\
\hline $\mathrm{C}$ & 2336 & (Intense group of type IfI's.) Small flare with bright surge. \\
\hline $\mathbf{C}$ & 2338 & Bright flare and large surge; repeat of 2330 UT on larger scale. \\
\hline
\end{tabular}


(a)
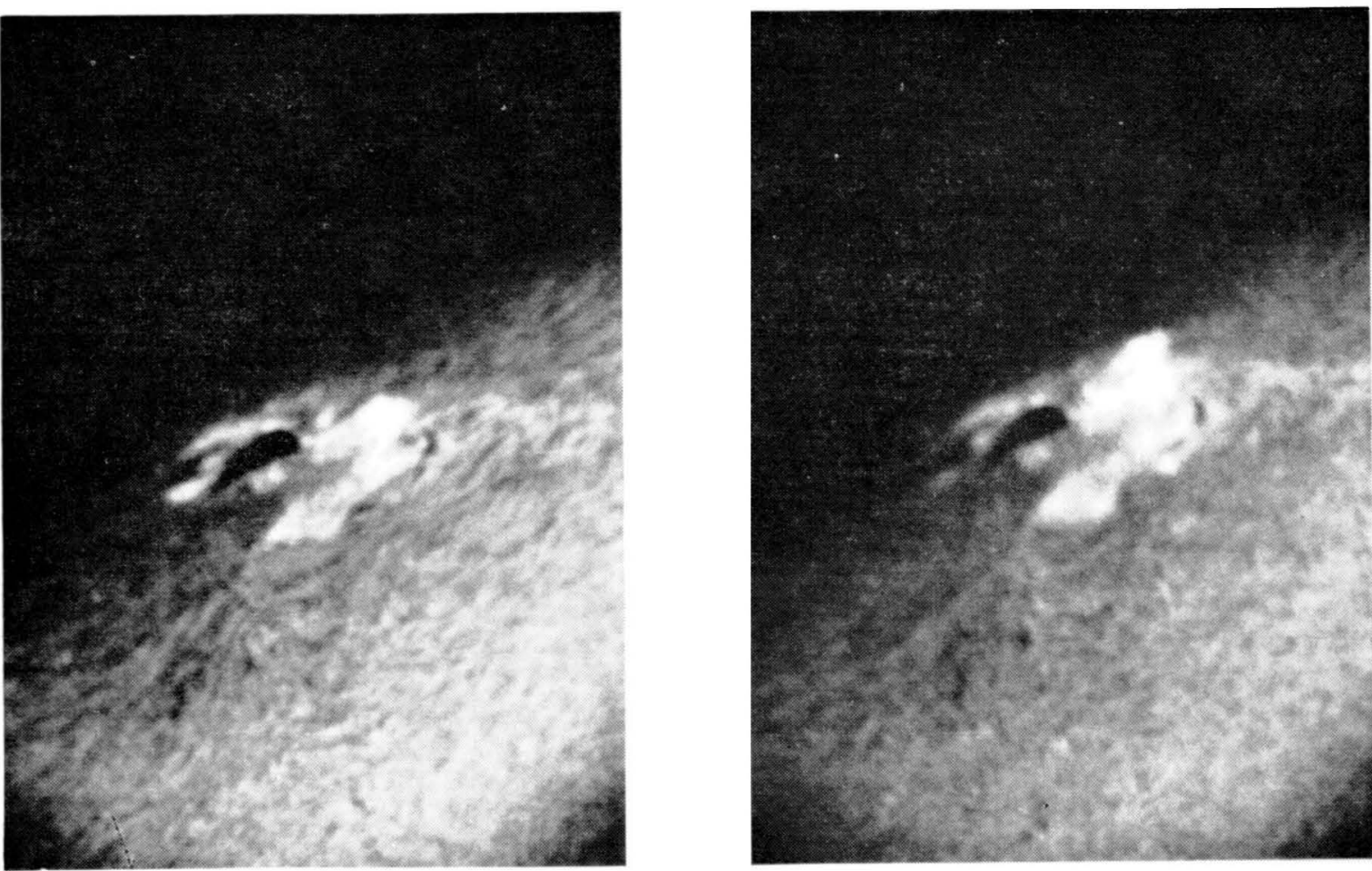

(b)
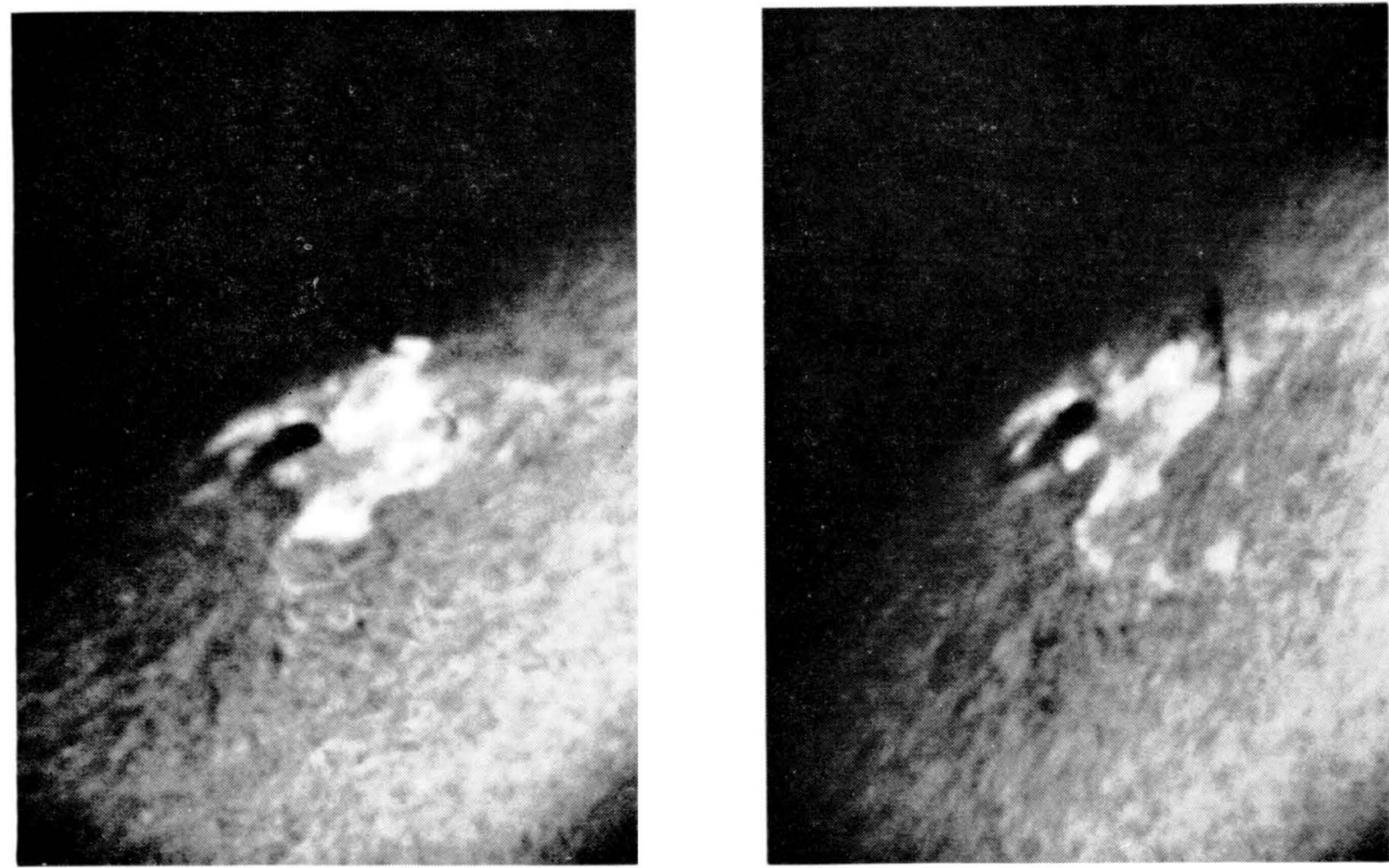

(d)

Fig. 27. Explosive flare from I', Sept. 25. (a) 2311 UT. A bright surge flare from C' (exact position not clear) at left precedes brightening at I', which (b) 2321 UT erupts in a spray (c) 2326 UT. Brightness spread through the region, with the eastward spread apparently limited by closed field structure in that direction. - (d) A loop prominence is seen dark against the disk to the right of the flare. A small flare at $\mathrm{C}$ is seen. 
servers. This is probably the same as the bright mound that appears above the limb and erupts in limb explosive flares.

\section{Conclusion}

We have given our main conclusions in section 1 and shall not repeat them here. We feel this study shows the value of detailed synoptic study of large scale cinematograms in understanding the structure of flares. It is not only important to know that a flare occurred in a region at a certain time, but where it occurred and what form it took. Our data show that the overall magnetic field structure of the region is merely deformed with the passage of time, and may be followed fairly easily. It is also clear that certain points in the field are more likely to have flares than others.

We wish to thank many colleagues who have contributed data: Dr. James W. Warwick, for radio data and valuable discussions; Dr. Vaclav Bumba, for his excellent white light photos; Dr. Neal R. Sheeley for his spectroheliograms; Mr. Harry Ramsey of Lockheed and Mr. Patrick McIntosh of Sacramento Peak Observatory. Mr. Stephen Schoolman helped with early analysis, and Dr. A. D. Fokker communicated his collected data. This research was begun by us at the High Altitude Observatory and was supported by the National Aeronautics and Space Administration. Above all, we thank the Climax observers, Keith Watson and Robert James for obtaining the movies.

\section{References}

Athay, R. C. and Moreton, G. E.: 1961, Ap. J. 133, 935.

Howard, R. F. and Harvey, J. W.: 1964, Ap. J. 139, 1328.

SeVErny, A. B.: 1958, Izv. Krim. Astrophys. Obs. 20, 22.

SEVERNY, A.: 1960, ibid., 22, 12.

Teske, R. G., Dodson, H., and Hedeman, E. R.: 1964, Ap. J. 139, 1336. 